\title{
RIOLITA DE SAN JOAQUÍN
}

\Cordillera Oriental Departamento de Santander

Gabriel Rodríguez, María Isabel Arango, Ana María Correa Martínez y Gilberto Zapata

Catálogo de las unidades litoestratigráficas de Colombia / Triásico - Jurásico

Citación: Rodríguez, G., Arango, M. I., Correa Martínez, A. M. y Zapata, G. (2020). Riolita de San Joaquín. En Catálogos de las unidades litoestratigráficas de Colombia: Macizo de Santander. Vol. 1. Servicio Geológico Colombiano. https://doi.org/10.32685/9789585279445.8 
La actividad magmática en el Macizo de Santander en el límite entre el Triásico y el Jurásico está evidenciada por vulcanismo y cuerpos intrusivos graníticos, cuerpos hipoabisales y riolítico-riodacítico que se emplazaron en un basamento metamórfico del Paleozoico. Los cuerpos magmáticos plutónicos son alargados y se orientan preferencialmente en dirección norte-noroeste, lo que concuerda con el rumbo de las fallas regionales, que marcan la tectónica del Macizo de Santander y delimitan las diferentes unidades.

La Riolita de San Joaquín es un cuerpo que surge como consecuencia del magmatismo de arco entre el Triásico y el Jurásico. En el catálogo de la Riolita de San Joaquín se incluyen los análisis petrográficos, químicos y una edad radiométrica $\mathrm{U} / \mathrm{Pb}$ de este plutón, lo que constituye un aporte al desarrollo del conocimiento geológico del país.

Los catálogos estratigráficos de Colombia tienen por objeto definir y describir unidades litológicas de la geología colombiana que han sido reconocidas mediante trabajos de cartografía y exponer el conocimiento geológico que se tiene de cada una de ellas.

\section{Proponente del nombre}

El nombre propuesto se atiene a las recomendaciones de la International Subcommission on Stratigraphic Classification of IUGS $(1987,1994)$.

La denominación Riolita de San Joaquín tiene en cuenta la litología dominante y el nombre geográfico, y es propuesto por los autores.

\section{Origen del nombre, distribución geográfica y reseña histórica}

El nombre de este cuerpo ígneo subvolcánico proviene de su composición modal dominante y de su localización geográfica, cerca de la cabecera municipal de San Joaquín (Santander), a unos $3 \mathrm{~km}$ al norte de esta localidad.

Aflora sobre la carretera que comunica a San Joaquín con la vereda La Aurora, en la plancha 136, Málaga, a escala 1:100.000. Se presenta como un cuerpo con un área aproximada de $20,9 \mathrm{~km}^{2}$, de forma tabular irregular, alongada, con dirección N-S (figura 1).

Este pequeño plutón no aparece en la cartografía regional de la plancha 136, Málaga. En el presente trabajo no solo se describe, sino que se cartografía y se define a partir de la composición química predominante, conservando el nombre del lugar geográfico más importante del área de afloramiento, de acuerdo con las recomendaciones de la International Subcommission on Stratigraphic Classification, ISSC (1987, 1994).

\section{Descripción geológica}

\subsection{Marco geológico}

El Macizo de Santander hace parte de un bloque regional triangular formado por las fallas de Santa Marta-Bucaramanga, en el lado occidental, la falla de Oca-Ancón, en el lado norte, y la falla de Boconó, en el lado oriental.

Las rocas más antiguas del Macizo de Santander comprenden unidades metamórficas como el Neis de Bucaramanga (Ward et al., 1973), también denominado Complejo Bucaramanga (Clavijo, 1994), constituido por paragneises migmatíticos de alto grado, considerados de edad proterozoica (García y Ríos, 1999; Ordóñez et al., 2006), con un pico de metamorfismo de edad $1057 \pm 28$ Ma U/Pb-Shrimp en circón, relacionada con la orogenia Grenvilliana. Sin embargo, estudios recientes reportan edades de metamorfismo de aproximadamente $477 \mathrm{Ma}$, relacionadas con la orogenia Caledoniana (Van der Lelij, 2013; Van der Lelij et al., 2016).

El Neis de Bucaramanga está cubierto por la Formación Silgará. Se compone de rocas del Proterozoico tardío al Paleozoico temprano, como ortoanfibolitas, esquistos, filitas, metalodolitas, metaareniscas y escasos mármoles (Ward et al., 1973; García y Ríos, 1999; Ríos et al., 2003; Mantilla et al., 2013). El metamorfismo presenta edades del Ordovícico inferior-medio relacionadas con la orogenia Caledoniana (Ríos et al., 2003; Ordóñez Cardona et al., 2006; Clavijo et al., 2008; Mantilla et al., 2013). 


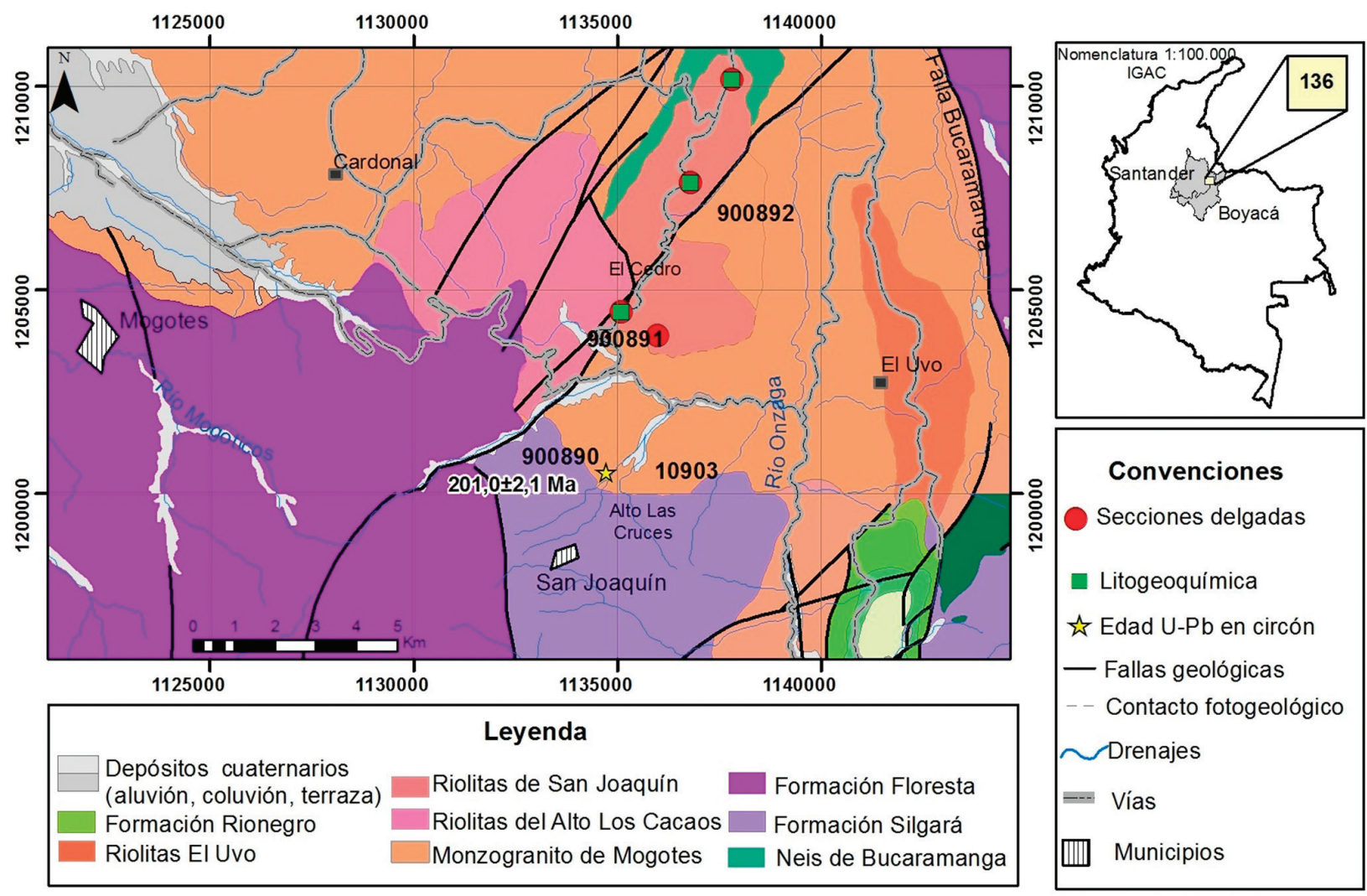

Figura 1. Mapa de localización de la Riolita de San Joaquín y del muestreo de rocas

Algunas edades U/Pb en circón indican un evento de magmatismo posterior al metamorfismo, representado por metavulcanitas y plutones que intruyen el basamento metamórfico, con edades $\mathrm{U} / \mathrm{Pb}$ en circón del Silúrico, Devónico inferior, Carbonífero y límite Triásico-Jurásico.

Los plutones triásico-jurásicos del Macizo de Santander se encuentran emplazados en rocas metamórficas paleozoicas, consideradas parte del Terreno Chibcha (Restrepo y Toussaint, 1988; Restrepo et al., 2011), o del Terreno Santander-Norte de Santander (Etayo et al., 1983).

Durante el límite Triásico-Jurásico se desarrolló un importante magmatismo hacia la margen occidental del Macizo de Santander, con el emplazamiento de grandes batolitos, stocks graníticos y cuerpos riolíticos subvolcánicos localizados dentro del basamento metamórfico, con desarrollo de contactos netos intrusivos.

Las unidades sedimentarias cretácicas reposan discordantemente sobre el basamento metamórfico y los plutones. Después de la sedimentación cretácica, du- rante el Mioceno se generó un escaso magmatismo que permitió el emplazamiento de pequeños cuerpos de pórfidos con mineralización de oro (Leal, 2011; Mantilla et al., 2013).

\subsection{Características macroscópicas}

La Riolita de San Joaquín corresponde a una roca masiva de color entre anaranjado y rosado, moteada de blanco y negro, porfirítica, constituida por fenocristales de plagioclasa de hasta $5 \mathrm{~mm}$, feldespato alcalino en cristales euhedrales rosados, cuarzo bipiramidal y biotita de 1 a $3 \mathrm{~mm}$, flotando en una matriz afanítica de color anaranjado claro a gris (figura 2).

Son comunes los afloramientos con desarrollo de saprolito de color anaranjado con parches de tonalidades blancas y verdosas y textura arenosa, con espesores de alteración de hasta $10 \mathrm{~m}$. Localmente desarrolla meteorización esferoidal con bolos métricos sobre la superficie del suelo y está atravesada por diques aplíticos con textura granular fina sacaroidal (figura 3). 


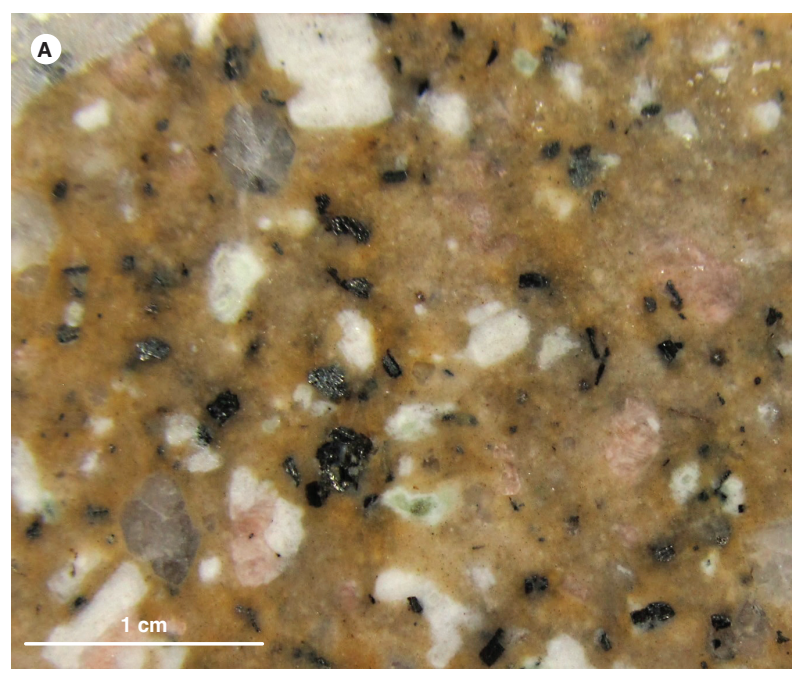

Figura 2. Aspecto macroscópico de rocas de la Riolita de San Joaquín A) IGM-900890 (GR-6729) y B) IGM-900892 (GR_6731).

\subsection{Características microscópicas}

Se analizaron tres secciones delgadas mediante conteo modal de 300 puntos. La clasificación de la roca obtenida por este método fue riolita, dacita y andesita, que presentan una textura porfídica y matriz felsítica a micrográfica; están constituidas por fenocristales de plagioclasa, feldespato alcalino, cuarzo y biotita, y como minerales accesorios, opacos, apatito, circón y epidota (tabla 1, figura 4).

El cuarzo se encuentra como fenocristales y como microcristales en la matriz, y en algunas rocas forma coronas con intercrecimientos gráficos. Los fenocristales son euhedrales a subhedrales inequigranulares de tamaños entre 0,25 y $4 \mathrm{~mm}$, limpios, con inclusiones de polvo a manera de líneas, incoloros, con birrefringencia máxima amarilla del primer orden. Pueden tener bahías de corrosión de la matriz, así como inclusiones de gotas de la matriz. Algunos cristales son bipiramidales, con los contornos corroídos por la matriz. En la matriz, el cuarzo desarrolla cristales esferulíticos que pueden estar inter-
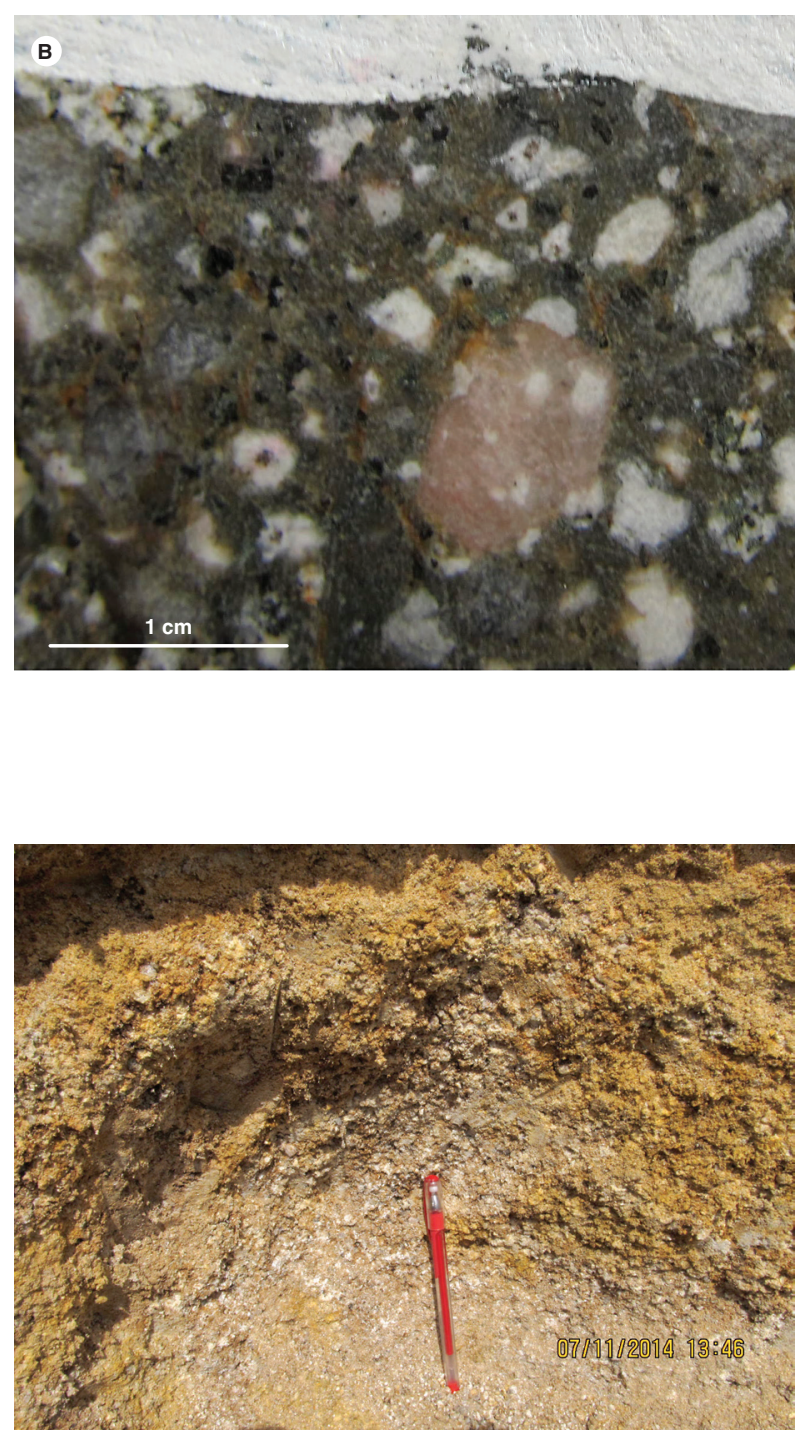

Figura 3. Aspecto macroscópico del saprolito de la Riolita de San Joaquín

crecidos con feldespato, formando texturas micrográficas (granofíricas) y coronas micrográficas alrededor de cristales de plagioclasa y feldespato. Con menos frecuencia, el cuarzo se presenta en cristales anhedrales intersticiales entre los esferulitos radiales micrográficos.

Tabla 1. Composición modal de rocas de la Riolita de San Joaquín

\begin{tabular}{|c|c|c|c|c|c|c|c|c|c|c|c|c|c|}
\hline IGM & N. ${ }^{\circ}$ campo & $\mathbf{x}$ & $\mathbf{Y}$ & Qtz & PI & Kfs & $\mathrm{Bt}$ & Op & Ap & Zrn & Ep & Matriz & Clasificación petrográfica \\
\hline 900890 & GR-6729 & 1135094 & 1204469 & 10,4 & 11,9 & 4,0 & 4,7 & 0,5 & $\operatorname{Tr}$ & $\operatorname{Tr}$ & & 68,9 & Fenodacita \\
\hline 900891 & GR-6730 & 1136800 & 1207641 & 7,8 & 26,6 & 13,0 & 3,9 & TR & $\mathrm{Tr}$ & $\operatorname{Tr}$ & & 48,7 & Fenoandesita \\
\hline 900892 & GR-6731 & 1137810 & 1210177 & 48,5 & 15,2 & 34,0 & 1,5 & 0,7 & $\operatorname{Tr}$ & $\operatorname{Tr}$ & $\operatorname{Tr}$ & & Riolita micrográfica \\
\hline
\end{tabular}


1 Traquita de feldespato alcalino

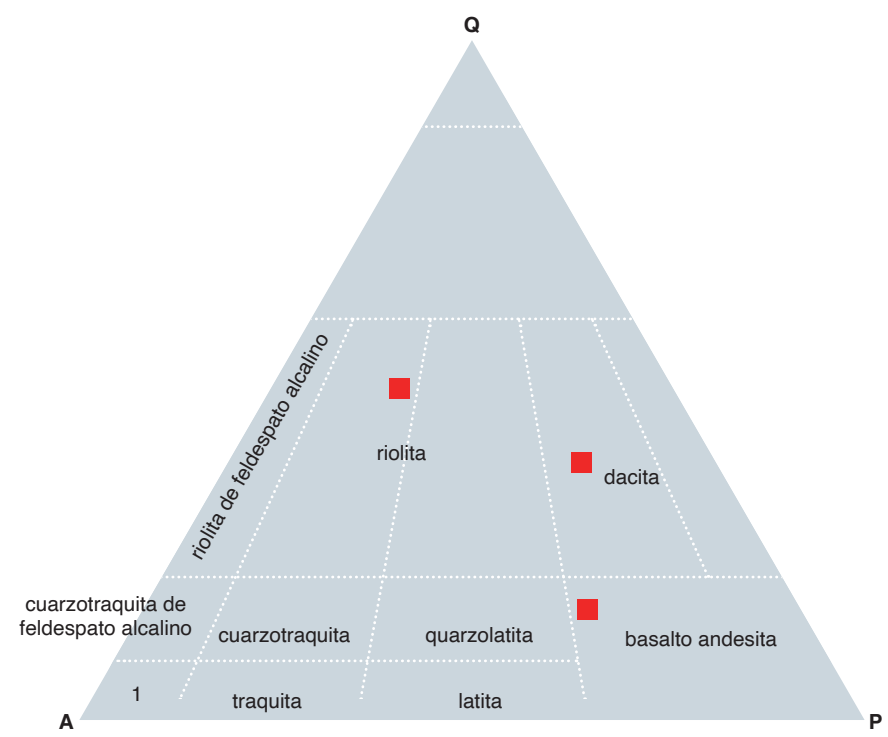

Figura 4. Clasificación modal de rocas de la Riolita de San Joaquín en el triángulo de Streckeisen (1978)

La plagioclasa se presenta en fenocristales y como microcristales en la matriz. Los fenocristales son euhedrales a subhedrales inequigranulares de tamaños entre 0,5 y $2,5 \mathrm{~mm}$, con maclas de albita, albita-Carlsbad, con los contornos corroídos por la matriz; los fenocristales pueden ser seriados, presentan los núcleos alterados, por lo general a arcilla, sericita y saussurita, y los bordes inalterados. En algunas rocas, los cristales microfracturados tienen alteración a gibbsita, presentan extinción zonada oscilatoria, pueden formar localmente glómero-fenocristales con cuarzo y biotita. El relieve de la plagioclasa es mayor que el del bálsamo y puede aparecer incluida en el feldespato alcalino.

El feldespato alcalino se clasificó como ortosa. Se presenta en fenocristales y como microcristales en la matriz. Los fenocristales son euhedrales a subhedrales inequigranulares de tamaños entre 0,5 y $5 \mathrm{~mm}$, con bordes corroídos por la matriz. Algunos cristales tienen maclas de tipo Carlsbad, con desmezclas pertíticas en parches, relieve menor que el del bálsamo; pueden tener bahías de corrosión, se alteran levemente (5\%) a caolín, con inclusiones de biotita, cuarzo y plagioclasa. Algunos cristales presentan crecimiento oscilatorio concéntrico y desmezclas pertíticas en filoncillos. En la matriz, el feldespato se presenta en algunas rocas como esferulitos radiales y plumosos micrográficos, de tamaños menores de 1,3 mm, con extinción en ojo de pájaro. Algunos cristales tienen formas irregulares y coronas micrográficas alrededor de microfenocristales y fenocristales.
La biotita se encuentra en fenocristales a manera de láminas euhedrales a subhedrales de tamaños que oscilan entre 0,20 y 1,4 mm, y como esqueletos de fenocristales alterados a clorita, con pleocroísmo X: amarillo pálido, Y-Z: pardo oscuro. Se altera levemente a clorita y titanita a lo largo del clivaje (5\% a $10 \%)$. Algunos cristales están flexionados, con los contornos corroídos por la matriz, y presentan extinción paralela; tienen inclusiones de cuarzo, circón y apatitos.

Los opacos corresponden a magnetita e ilmenita. La magnetita aparece en microcristales anhedrales en la matriz, que le imprimen un aspecto moteado; también en microfenocristales anhedrales de entre 0,1 y 0,2 mm, con bordes irregulares dispersos en la pasta, donde se altera a hematita. Con luz reflejada presenta color gris con reflectancia baja. Puede formar agrupaciones de cristales y tiene microfracturas internas y bordes rectos cristalinos.

La ilmenita se encuentra en microfenocristales anhedrales con bordes rectos, tamaños entre 0,1 y $0,2 \mathrm{~mm}$, textura local esquelética. A la luz reflejada es de color gris con reflectancia baja, tiene bordes rectos cristalinos y buen desarrollo de clivaje.

Los microcristales de circón son euhedrales a subhedrales, aparecen incluidos en fenocristales de biotita y junto a opacos, con birrefringencia del límite entre el segundo y el tercer orden; algunos son prismáticos y su tamaño es menor de $0,1 \mathrm{~mm}$.

El apatito se encuentra como microcristales euhedrales a subhedrales, incluidos principalmente en biotita y en 
los fenocristales. Es incoloro, de relieve alto y tiene birrefringencia gris de la parte baja del primer orden, en cortes basales hexagonales y longitudinales alargados, de hasta $0,25 \mathrm{~mm}$ en el eje mayor, y ancho de hasta 0,2 $\mathrm{mm}$.

La allanita puede estar presente en algunas rocas en cristales euhedrales finos de entre 0,1 y $0,2 \mathrm{~mm}$, de for- mas hexagonales, con bordes rectos. Su color es marrón y presenta un pleocroísmo de tonos marrones de claro a medio.

Algunas rocas contienen amígdalas de formas irregulares rellenas de cristales de cuarzo y epidota de color amarillo pálido.
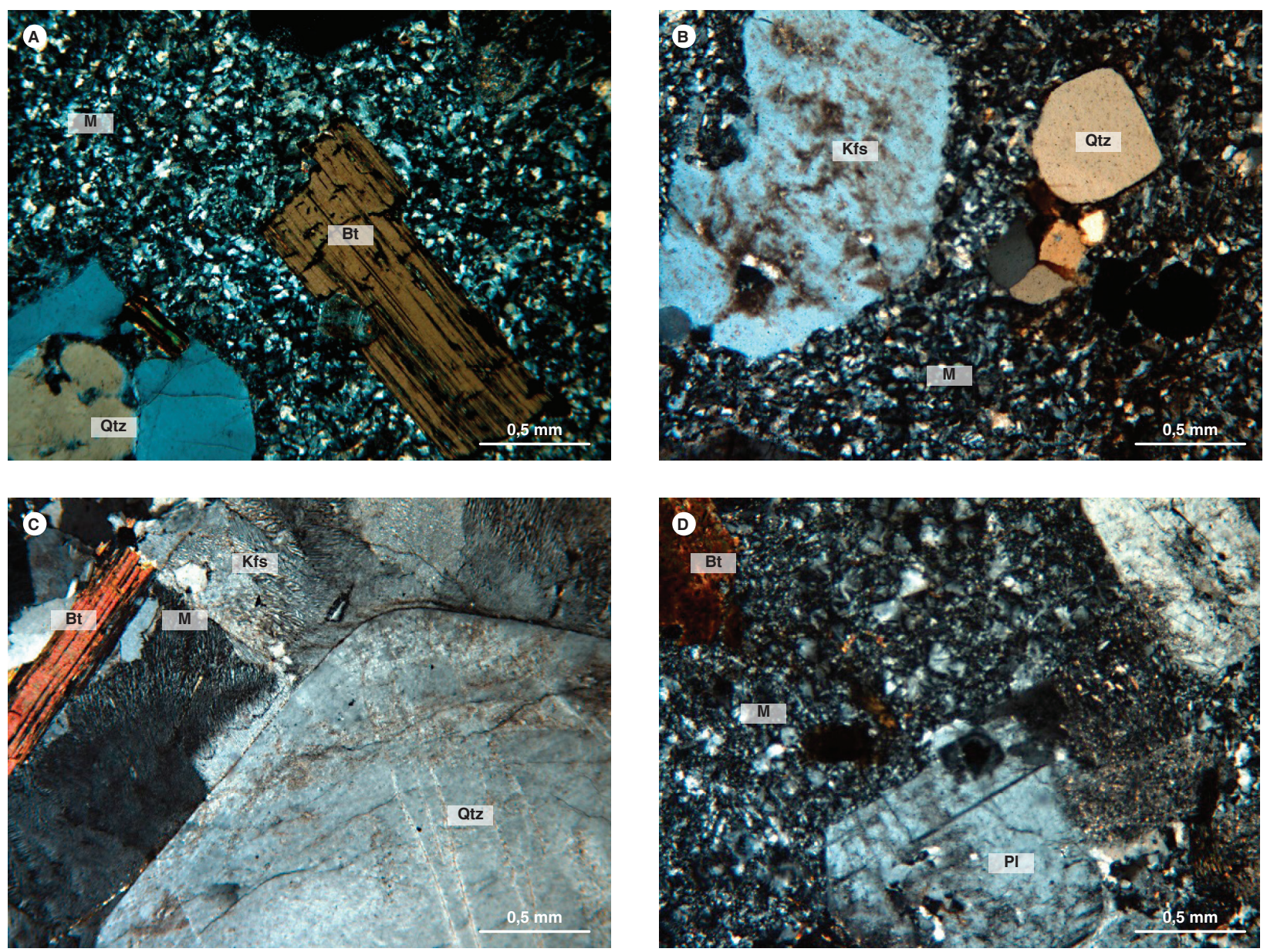

Figura 5. Aspecto general de la Riolita de San Joaquín

A y B) IGM-900890 (GR-6729), dacita. Nícoles cruzados. Fenocristales de biotita (Bt), feldespato (Kfs) y cuarzo (Qtz) en matriz felsítica microcristalina (M). C) IGM-900892 (GR-6731), riolita micrográfica. Nícoles cruzados. Fenocristales de feldespato alcalino (Kfs) y biotita (Bt) en matriz micrográfica (M). D) IGM-900891, fenoandesita. Nícoles cruzados. Fenocristales de plagioclasa (PI) y biotita (Bt) flotando en matriz vítrea con esferulitos de feldespato (M).

La matriz puede ser felsítica, micrográfica o vítrea desvitrificada. En el primer caso está constituida por un mosaico microcristalino anhedral felsítico de microcristales de cuarzo y feldespato, junto a microcristales de opacos de igual tamaño y escasas láminas de biotita dispersas en la matriz. En el segundo caso, la matriz está constituida por intercrecimientos micrográficos de cuarzo y feldespatos que localmente forman esferulitos radiales y coronas alrededor de fenocristales. Los inter- crecimientos ocupan los espacios entre los cristales y fenocristales. La matriz vítrea, constituida por vidrio incoloro, se desvitrifica a agregados o microcristales anhedrales de cuarzo y feldespatos.

\subsection{Química mineral}

Para este análisis se seleccionó la muestra IGM-900890 (GR-6729), clasificada petrográficamente como dacita. Se realizó análisis químico en feldespato alcalino, pla- 
gioclasa y biotita. Los resultados de la química mineral en feldespato y plagioclasa se muestran en la figura $6 \mathrm{y}$ la tabla 2.

De la muestra GR-6729 se analizó un cristal de feldespato alcalino (figura 7C); los resultados se resumen en la figura 6. El feldespato potásico de la muestra GR6729 exhibe micropertitas en filoncillo que se pueden apreciar en la imagen del cristal analizado (figura 7C), y corresponden al límite entre pertita y ortosa pertítica. En el campo C3 la composición es Or 55-85,5, Ab 1414,8, An 0,23-0,50.

De la muestra GR-6729 se analizaron dos cristales de plagioclasa (figura 7 A y B), con cuatro y cinco puntos distribuidos en cada cristal. Del campo C2 se obtuvo una composición de plagioclasa de tipo oligoclasa a andesina sódica (Ab 64,8-70,8, An 24,6-31,9, Or 3,3-4,6), y del campo C4, una composición de andesina (Ab 52,4-62,7, An 34-45,3, Or 2,3-3,2), con una notable variación interna dentro del mismo cristal.

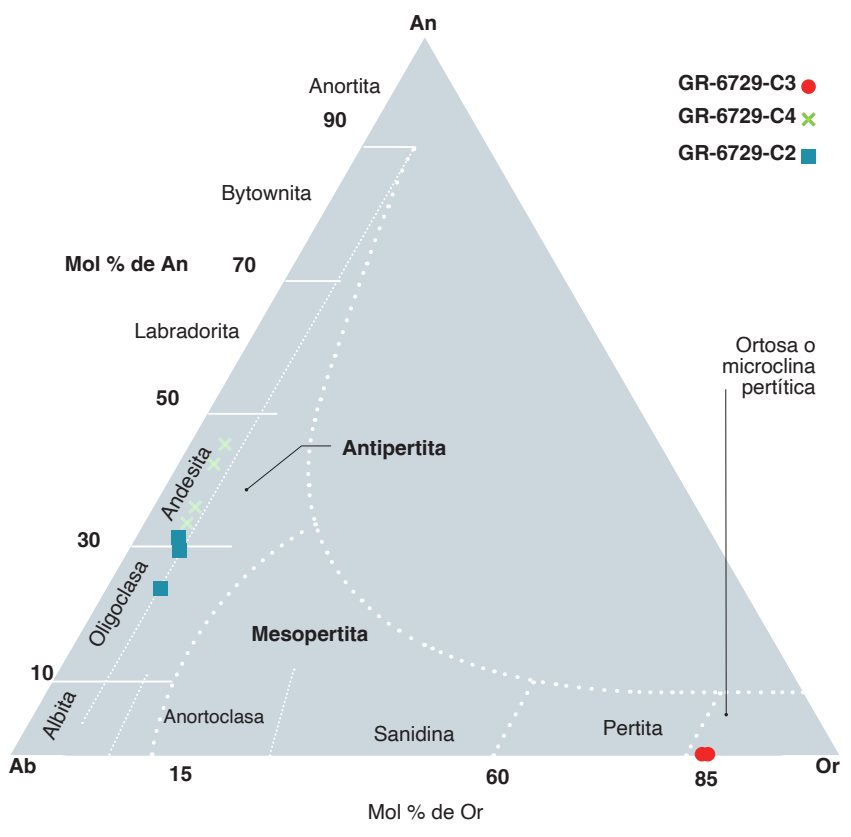

Figura 6. Composición del feldespato potásico y plagioclasas de la Riolita de San Joaquín

Diagrama de Smith-Brown (1988).

Tabla 2. Análisis de cristales de feldespato alcalino y plagioclasa de la muestra GR-6729

\begin{tabular}{|c|c|c|c|c|c|c|c|c|c|c|c|c|}
\hline & $\begin{array}{l}\text { GR-6729- } \\
\text { C3-Kfs-1 }\end{array}$ & $\begin{array}{l}\text { GR-6729- } \\
\text { C3-Kfs-2 }\end{array}$ & $\begin{array}{l}\text { GR-6729- } \\
\text { C3-Kfs-3 }\end{array}$ & $\begin{array}{c}\text { GR-6729- } \\
\text { C4-PI-1 }\end{array}$ & $\begin{array}{c}\text { GR-6729- } \\
\text { C4-PI-2 }\end{array}$ & $\begin{array}{c}\text { GR-6729- } \\
\text { C4-PI-3 }\end{array}$ & $\begin{array}{c}\text { GR-6729- } \\
\text { C4-PI-4 }\end{array}$ & $\begin{array}{c}\text { GR-6729- } \\
\text { C2-PI1 }\end{array}$ & $\begin{array}{c}\text { GR-6729- } \\
\text { C2-PI2 }\end{array}$ & $\begin{array}{c}\text { GR-6729- } \\
\text { C2-PI3 }\end{array}$ & $\begin{array}{c}\text { GR-6729- } \\
\text { C2-PI4 }\end{array}$ & $\begin{array}{c}\text { GR-6729- } \\
\text { C2-PI5 }\end{array}$ \\
\hline $\mathrm{SiO}_{2}$ & 1,64 & 1,59 & 1,54 & 58,11 & 56,58 & 55,73 & 58,19 & 61,38 & 60,46 & 59,56 & 60,69 & 60,35 \\
\hline $\mathrm{TiO}_{2}$ & 0,00 & 0,00 & 0,00 & 0,02 & 0,01 & 0,02 & 0,01 & 0,00 & 0,01 & 0,00 & 0,00 & 0,02 \\
\hline $\mathrm{Al}_{2} \mathrm{O}_{3}$ & 18,53 & 18,53 & 18,49 & 26,42 & 27,33 & 28,06 & 26,32 & 24,82 & 25,66 & 26,04 & 24,92 & 25,22 \\
\hline $\mathrm{FeO}$ & 66,01 & 65,35 & 65,60 & 0,28 & 0,39 & 0,32 & 0,27 & 0,43 & 0,52 & 0,54 & 0,50 & 0,54 \\
\hline $\mathrm{MgO}$ & 0,06 & 0,05 & 0,10 & 0,00 & 0,00 & 0,00 & 0,00 & 0,00 & 0,04 & 0,00 & 0,03 & 0,00 \\
\hline $\mathrm{CaO}$ & $-0,01$ & 0,02 & $-0,03$ & 7,47 & 8,37 & 8,87 & 6,97 & 4,81 & 6,06 & 6,49 & 5,99 & 6,15 \\
\hline $\mathrm{Na}_{2} \mathrm{O}$ & 14,36 & 14,48 & 14,31 & 6,90 & 6,01 & 5,67 & 7,09 & 7,67 & 7,13 & 7,29 & 7,32 & 7,58 \\
\hline $\mathrm{K}_{2} \mathrm{O}$ & 0,20 & 0,25 & 0,17 & 0,53 & 0,40 & 0,38 & 0,55 & 0,75 & 0,66 & 0,56 & 0,77 & 0,74 \\
\hline Total & 100,79 & 100,24 & 100,16 & 99,72 & 99,08 & 99,06 & 99,40 & 99,87 & 100,53 & 100,48 & 100,22 & 100,60 \\
\hline $\mathrm{Si}$ & 12,02 & 11,98 & 12,01 & 10,43 & 10,24 & 10,10 & 10,47 & 10,91 & 10,71 & 10,59 & 10,79 & 10,72 \\
\hline $\mathrm{Al}$ & 3,98 & 4,00 & 3,99 & 5,59 & 5,83 & 5,99 & 5,58 & 5,20 & 5,36 & 5,46 & 5,22 & 5,28 \\
\hline $\mathrm{Ti}$ & 0,00 & 0,00 & 0,00 & 0,03 & 0,04 & 0,03 & 0,03 & 0,04 & 0,05 & 0,05 & 0,05 & 0,05 \\
\hline $\mathrm{Fe}^{2+}$ & 0,02 & 0,03 & 0,02 & 0,00 & 0,00 & 0,00 & 0,00 & 0,00 & 0,00 & 0,00 & 0,00 & 0,00 \\
\hline $\mathrm{Mg}$ & 0,00 & 0,00 & 0,00 & 0,00 & 0,00 & 0,00 & 0,00 & 0,00 & 0,01 & 0,00 & 0,01 & 0,00 \\
\hline $\mathrm{Na}$ & 0,58 & 0,57 & 0,55 & 2,40 & 2,11 & 1,99 & 2,47 & 2,64 & 2,45 & 2,51 & 2,52 & 2,61 \\
\hline $\mathrm{Ca}$ & 0,01 & 0,01 & 0,02 & 1,44 & 1,62 & 1,72 & 1,34 & 0,92 & 1,15 & 1,24 & 1,14 & 1,17 \\
\hline $\mathrm{K}$ & 3,34 & 3,39 & 3,34 & 0,12 & 0,09 & 0,09 & 0,13 & 0,17 & 0,15 & 0,13 & 0,17 & 0,17 \\
\hline Total & 19,94 & 19,98 & 19,93 & 20,02 & 19,93 & 19,93 & 20,02 & 19,88 & 19,88 & 19,97 & 19,92 & 20,00 \\
\hline$z$ & 15,99 & 15,99 & 16,00 & 16,06 & 16,11 & 16,12 & 16,08 & 16,15 & 16,12 & 16,10 & 16,07 & 16,05 \\
\hline$x$ & 3,95 & 3,99 & 3,93 & 3,96 & 3,82 & 3,81 & 3,94 & 3,73 & 3,76 & 3,87 & 3,85 & 3,95 \\
\hline Or & 84,96 & 85,50 & 85,53 & 3,06 & 2,39 & 2,32 & 3,22 & 4,57 & 3,96 & 3,27 & 4,53 & 4,26 \\
\hline$A b$ & 14,76 & 14,27 & 13,97 & 60,66 & 55,15 & 52,40 & 62,71 & 70,85 & 65,34 & 64,84 & 65,73 & 66,09 \\
\hline $\mathrm{An}$ & 0,28 & 0,23 & 0,50 & 36,28 & 42,47 & 45,29 & 34,07 & 24,58 & 30,70 & 31,89 & 29,74 & 29,65 \\
\hline Total & 100,00 & 100,00 & 100,00 & 100,00 & 100,00 & 100,00 & 100,00 & 100,00 & 100,00 & 100,00 & 100,00 & 100,00 \\
\hline
\end{tabular}



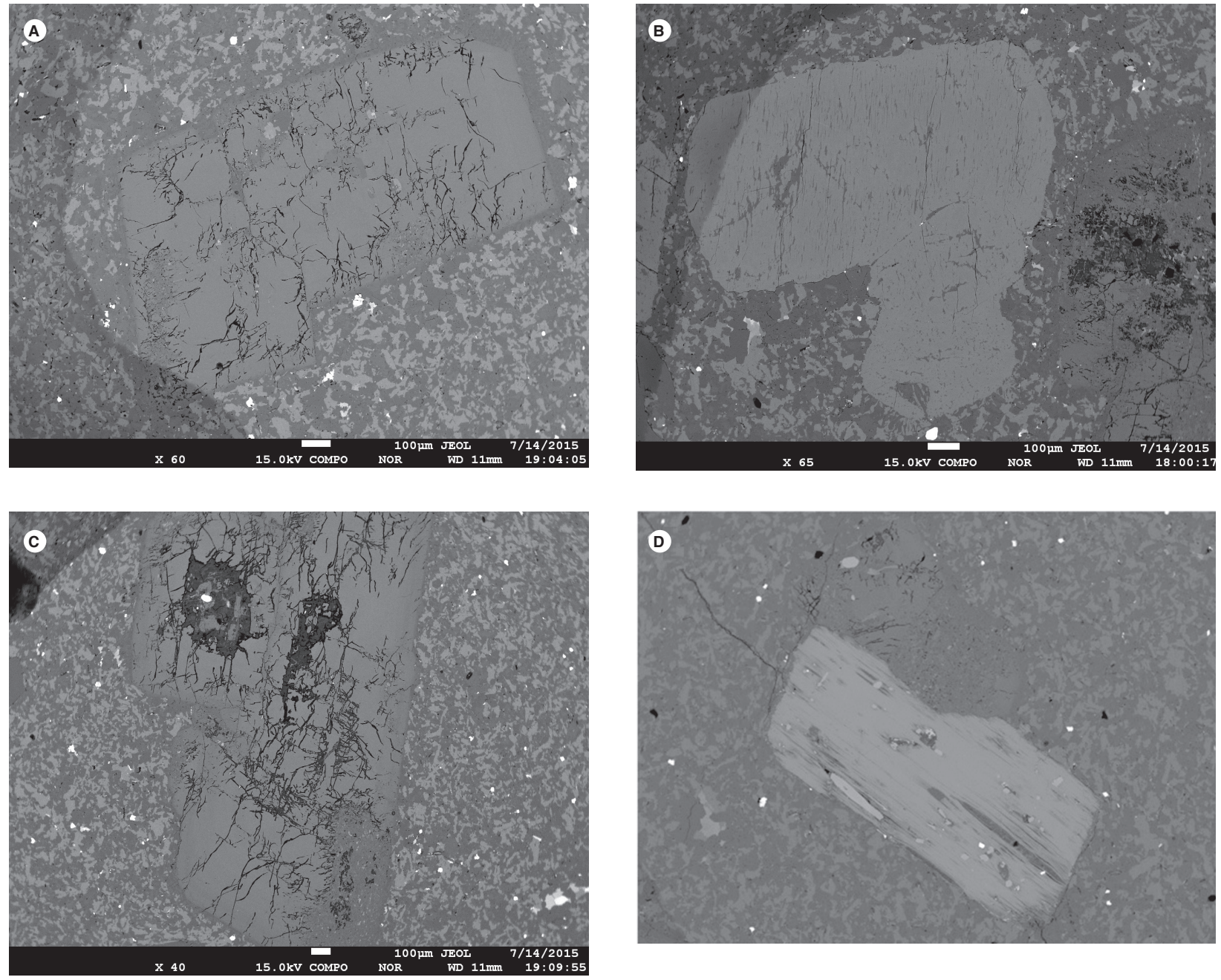

Figura 7. Imagen de electrones retrodispersados

A y B) Cristales de plagioclasa en los campos C4 y C2. C) cristal de feldespato alcalino en el campo C3. D) cristal de biotita de la muestra GR-6729.

\section{Litogeoquímica}

La caracterización litogeoquímica de la Riolita de San Joaquín se realizó a partir de tres (3) muestras clasificadas como riolita, dacita y andesita (GR-6729, GR-6730 y GR6731). Los análisis químicos se hicieron en el laboratorio del Servicio Geológico Colombiano, sede Bogotá. En los óxidos mayores se utilizó el método de fluorescencia de rayos X y se incluyeron los elementos traza $\mathrm{V}, \mathrm{Mo}, \mathrm{Nb}, \mathrm{Ta}$, $\mathrm{W}, \mathrm{Zr}$ y Hf, y en el resto de elementos traza y tierras raras se utilizó el equipo de espectrometría de masas con plasma acoplado inductivamente (ICP-MS). Para la interpretación de los óxidos mayores se hizo el recalculo, teniendo en cuenta los valores de LOI (pérdidas por ignición). Los resultados de óxidos mayores se muestran en la tabla 3.

Los análisis se realizaron con un espectrómetro de fluorescencia de rayos X, FRX, Panalytical AXIOS Mine- ral para análisis elemental, configurado con software especializado para materiales geológicos. La cuantificación de los óxidos mayores se realizó en muestra fundida con metaborato y tetraborate de litio, y la cuantificación de elementos menores se realiza en muestra prensada. En el análisis de elementos traza de interés geoquímico en rocas se usó un espectrómetro de masas con plasma inductivamente acoplado, ICP-MS, Perkin Elmer Nexion. Para la disolución de la muestra se realiza un ataque por pasos utilizando ácidos inorgánicos fuertes $\left(\mathrm{HF}, \mathrm{HNO}_{3}\right.$, $\mathrm{HClO}_{4}$ y $\mathrm{HCl}$ ). El proceso se realiza en sistema abierto, empleando distintas rampas de temperatura y tiempos de calentamiento. Gran parte de los diagramas geoquímicos se generaron con el uso del GCDKit versión 4.0 (Janoušek et al., 2006). 
Tabla 3. Composición de óxidos mayores en rocas de la Riolita de San Joaquín

\begin{tabular}{|c|c|c|c|c|c|c|c|c|c|c|c|c|c|c|}
\hline IGM & N. ${ }^{\circ}$ campo & w & $\mathrm{N}$ & $\mathrm{SiO}_{2}$ & $\mathrm{TiO}_{2}$ & $\mathrm{Al}_{2} \mathrm{O}_{3}$ & $\mathrm{Fe}_{2} \mathrm{O}_{3}$ & MgO & $\mathrm{CaO}$ & $\mathrm{Na}_{2} \mathrm{O}$ & $\mathrm{K}_{2} \mathrm{O}$ & MnO & LOI & Suma \\
\hline 900890 & GR-6729 & 1135098 & 1204469 & 68,54 & 0,63 & 16,54 & 2,46 & 0,20 & 1,58 & 4,41 & 4,25 & 0,10 & 0,38 & 99,15 \\
\hline 900891 & GR-6730 & 1136804 & 1207641 & 69,56 & 0,62 & 17,23 & 2,13 & 0,18 & 1,03 & 2,39 & 4,97 & 0,07 & 1,14 & 99,36 \\
\hline 900892 & GR-6731 & 1137814 & 1210177 & 65,40 & 0,28 & 18,16 & 3,10 & 0,55 & 1,79 & 4,16 & 4,37 & 0,13 & 0,78 & 98,80 \\
\hline
\end{tabular}

\section{1. Óxidos mayores}

Los valores de $\mathrm{SiO}_{2}$ en rocas de la Riolita de San Joaquín varían entre 65,40\% y 69,6\%; los valores de $\mathrm{Al}_{2} \mathrm{O}_{3}, \mathrm{Fe}_{2} \mathrm{O}_{3}$, $\mathrm{MgO}, \mathrm{Na}_{2} \mathrm{O}$ y $\mathrm{CaO}$ disminuyen con el aumento de $\mathrm{SiO}_{2}$; el $\mathrm{K}_{2} \mathrm{O}$ varía entre 4,3\% y 4,97\%; el CaO varía entre 1,03 y $1,6 \%, \mathrm{MgO}<1 \%$ y TiO $2<0,65 \%$; el contenido de $\mathrm{Al}_{2} \mathrm{O}_{3}$ es de 16,5 a $18,2 \%$; los valores de $\mathrm{Fe}_{2} \mathrm{O}_{3}$ son bajos, y varían entre $2,13 \%$ y $3,10 \%$, algo acorde con el bajo contenido de minerales ferromagnesianos; presentan contenido de álcalis $\left(\mathrm{Na}_{2} \mathrm{O}+\mathrm{K}_{2} \mathrm{O}\right)$ entre 7,4 y $8,7 \%$.

En los diagramas $\mathrm{K}_{2} \mathrm{O}$ versus $\mathrm{SiO}_{2}$ (Peccerillo y Taylor, 1976; Hastie et al., 2007), las rocas de la Riolita de San Joaquín se encuentran en la serie calcoalcalina alta en K y shoshonítica. La muestra IGM-900890 (GR6729) se inscribe en la serie calcoalcalina alta en $\mathrm{K}$, y se separa de las otras dos muestras (IGM-900891, GR-6731 y IGM-900892, 6Z-6732), que pertenecen al campo de la serie shoshonítica (figura $8 \mathrm{~A} \mathrm{y} \mathrm{B}$ ).

Las rocas de la Riolita de San Joaquín son subalcalinas, químicamente se clasifican en los campos de riolita y dacita en el diagrama TAS de Le Bas et al., (1986) (figura $8 \mathrm{C}$ ), con buena concordancia con la clasificación petrográfica.

Las riolitas y dacitas grafican en el campo peraluminoso del gráfico de Shand (1943), con valores de A/NK > 1 y valores de $\mathrm{A} / \mathrm{CNK}>1$, lo que sugiere aporte al magma de material de corteza continental, con valores altos de $\mathrm{SiO}_{2}>65 \%$ (figura $8 \mathrm{D}$ ). En el diagrama de Debon y Le Fort (1983) modificado por Villaseca et al., (1998) (figura 8E), las rocas se agrupan en el campo altamente y medianamente peraluminoso (h-P y m-P). El índice de saturación de alúmina en la mayoría de rocas oscila entre 1 y 2; en la relación $\mathrm{A} / \mathrm{CNK}>1$, tienen valores de $\mathrm{A} / \mathrm{NK}$ entre 1 y 2 ; la relación $\mathrm{K}_{2} \mathrm{O} / \mathrm{Na}_{2} \mathrm{O}$ presenta una variación de 0,48 a 1,04, y el $\mathrm{Al}_{2} \mathrm{O}_{3}>\mathrm{CaO}+\mathrm{Na}_{2} \mathrm{O}+\mathrm{K}_{2} \mathrm{O}$. De acuerdo con el diagrama AFM de Irvine y Baragar (1971) (figura 8 F), las rocas hacen parte de las series calcoalcalinas.

\subsection{Elementos traza y tierras raras}

En la tabla 4 se resumen los resultados de los análisis químicos de elementos traza y tierras raras correspondientes a las rocas de la Riolita de San Joaquín.

El diagrama de elementos de las tierras raras (REE) normalizado a condrito según los valores de Nakamura (1974) (figura 9A) muestra un enriquecimiento en tierras raras livianas (LREE) de más de cien veces respecto al valor del condrito, con un patrón paralelo y homogéneo que se va empobreciendo progresivamente hacia las tierras raras pesadas (HREE); un tren subhorizontal entre disprosio (Dy) y lutecio (Lu), comportamiento normal de las rocas generadas en ambientes de subducción (Wilson, 1991). 
A

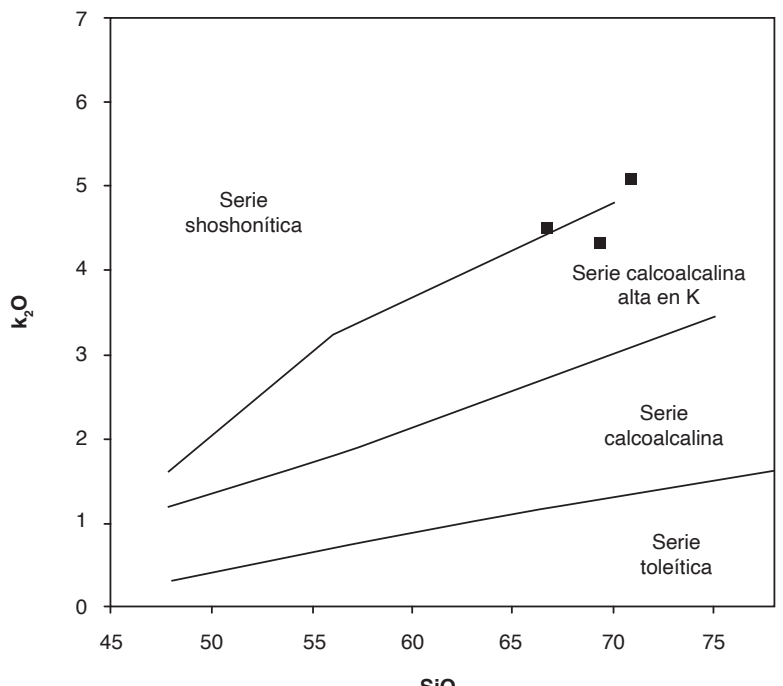

C

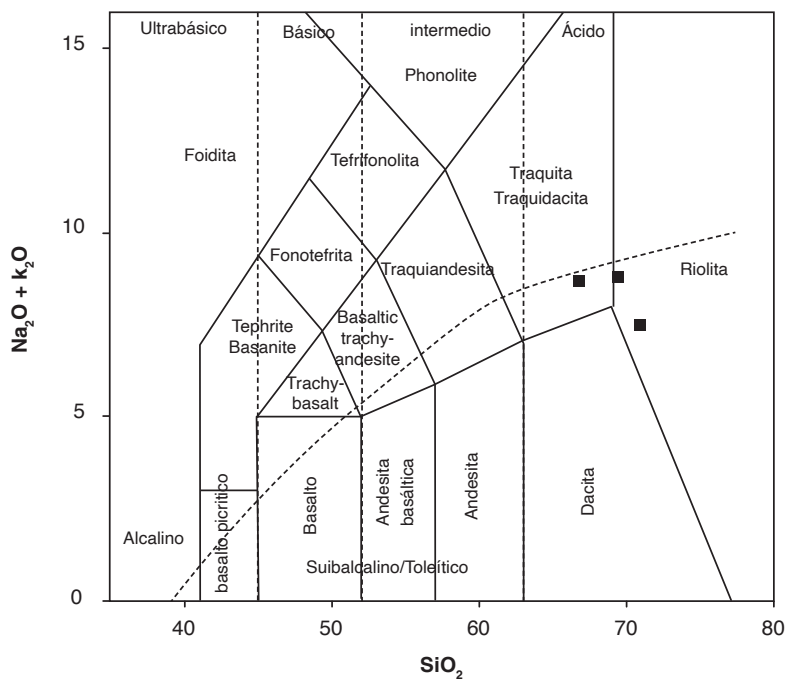

E

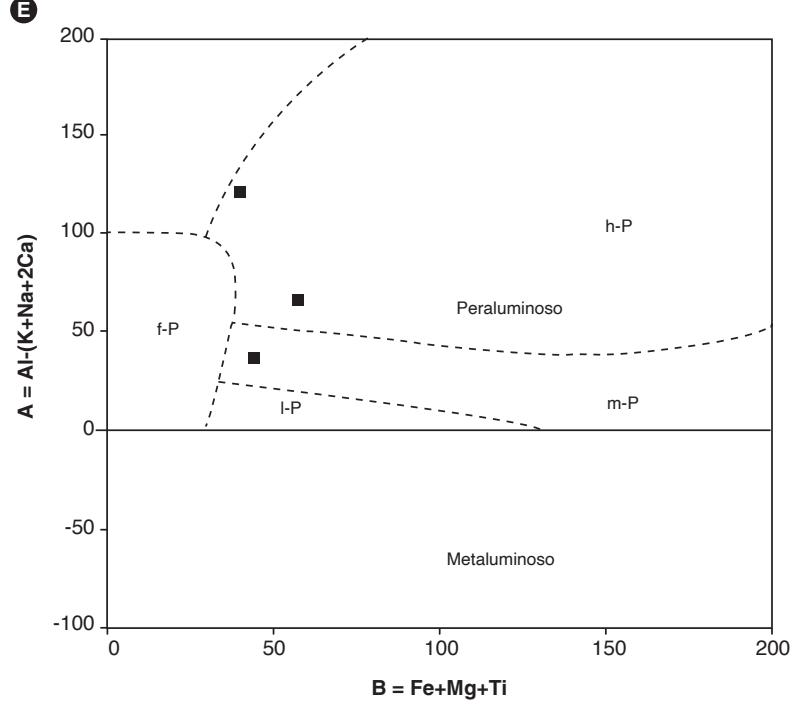

B

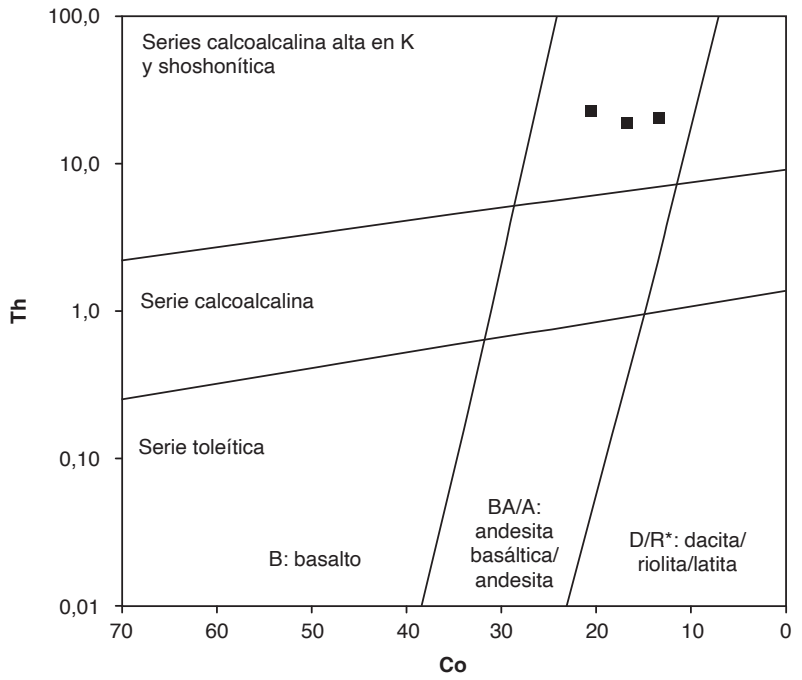

(D)

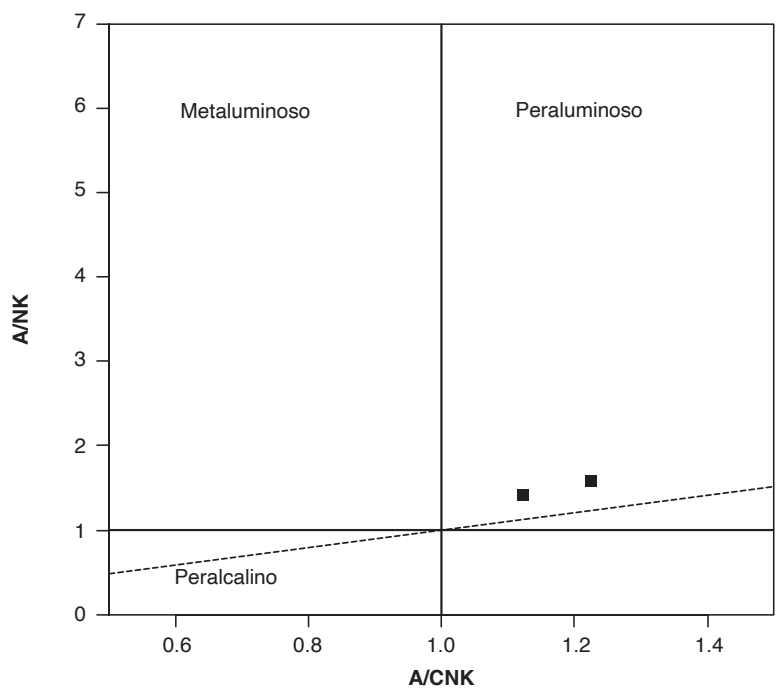

$\boldsymbol{F}$

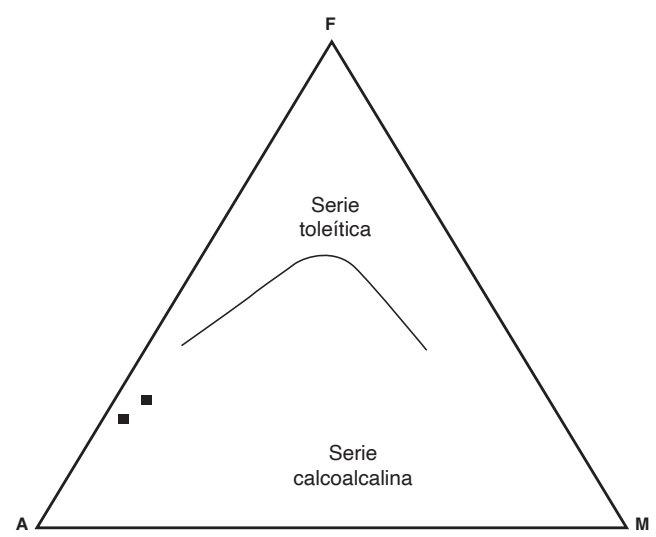

Figura 8. Diagramas de clasificación química de rocas de la Riolita de San Joaquín

A) Diagrama $\mathrm{K}_{2} \mathrm{O}$ vs. $\mathrm{SiO}_{2}$ (Peccerillo y Taylor, 1976). B) Diagrama de clasificación Th-Co (Hastie et al., 2007). C) Diagrama TAS de Le Bas et al. (1986). D) Diagrama de Shand (1943). E) Diagrama de Debon y Le Fort (1983) modificado por Villaseca et al. (1998), donde f-P granitoides peraluminosos félsicos, h-P granitoides altamente peraluminoso, m-P granitoides medianamente peraluminosos. F) Diagrama AFM de Irvine y Baragar (1971). 
Tabla 4. Resultados de elementos traza y tierras raras en rocas de la Riolita de San Joaquín

\begin{tabular}{|c|c|c|c|c|c|c|c|c|c|c|c|c|c|c|c|c|c|c|c|c|c|}
\hline IGM & N. ${ }^{\circ}$ campo & $\mathrm{Li}$ & $\mathrm{Be}$ & Sc & v & $\mathrm{Cr}$ & Co & $\mathrm{Ni}$ & $\mathrm{Cu}$ & $\mathrm{Zn}$ & $\mathrm{Ga}$ & As & $\mathbf{R b}$ & $\mathrm{Sr}$ & Cd & In & Cs & $\mathrm{Ba}$ & La & $\mathrm{Ce}$ & $\operatorname{Pr}$ \\
\hline 900890 & GR-6729 & 21 & 6 & 11 & 15 & 6,6 & 21 & 3,1 & 4,9 & 36 & 18 & 3 & 192 & 172 & 0,1 & 0 & 1,7 & 1.025 & 49 & 98 & 12 \\
\hline 900891 & GR-6730 & 29 & 3 & 9,7 & 13 & 3,2 & 13 & 3,9 & 4,9 & 32 & 17 & 3 & 186 & 124 & 0,1 & 0 & 2,1 & 916 & 67 & 122 & 15 \\
\hline 900892 & GR-6731 & 44 & 4 & 12 & 27 & 5,6 & 17 & 4 & 8,7 & 59 & 18 & 2,5 & 167 & 213 & 0,1 & 0,1 & 2,5 & 1.409 & 59 & 115 & 14 \\
\hline \multirow{2}{*}{\multicolumn{2}{|c|}{ Límites }} & $\mathrm{ppm}$ & $\mathrm{ppm}$ & $\mathrm{ppm}$ & $(\mathrm{mg} / \mathrm{kg})$ & $\mathrm{ppm}$ & $\mathrm{ppm}$ & $\mathrm{ppm}$ & $\mathrm{ppm}$ & $\mathrm{ppm}$ & $\mathrm{ppm}$ & $\mathrm{ppm}$ & $\mathrm{ppm}$ & $\mathrm{ppm}$ & $\mathrm{ppm}$ & & $\mathrm{ppm}$ & ppm & $\mathrm{ppm}$ & $\mathrm{ppm}$ & $\mathrm{ppm}$ \\
\hline & & 0,5 & 0,1 & 0,1 & 0,2 & 0,5 & 0,8 & 0,5 & 1 & 4 & 0,2 & 0,4 & 0,2 & 1 & 0,08 & & 0,1 & 1 & 0,1 & 0,1 & 0,1 \\
\hline IGM & N. ${ }^{\circ}$ campo & $\mathrm{Nd}$ & Sm & Eu & Gd & $\mathrm{Tb}$ & Dy & Ho & $\mathrm{Er}$ & $\mathrm{Tm}$ & $\mathrm{Yb}$ & Lu & TI & $\mathrm{Pb}$ & $\mathrm{Bi}$ & Th & U & $\mathrm{Zr}$ & $\mathrm{Nb}$ & w & \\
\hline 900890 & GR-6729 & 42 & 8 & 1,3 & 6 & 1,1 & 6 & 1,2 & 3,8 & 0,5 & 3,6 & 0,5 & 1,1 & 25 & 0,1 & 22 & 4,6 & 169 & 18 & 80 & \\
\hline 900891 & GR-6730 & 52 & 10 & 1,6 & 7 & 1,3 & 6,1 & 1,2 & 3,8 & 0,5 & 2,9 & 0,4 & 1,1 & 21 & 0,5 & 19 & 3,5 & 178 & 15 & 45 & \\
\hline 900892 & GR-6731 & 45 & 9 & 1,6 & 6 & 1,2 & 5,6 & 1,1 & 3,3 & 0,5 & 3 & 0,5 & 1 & 19 & 0,1 & 19 & 4,3 & 226 & 16 & 53 & \\
\hline \multirow{2}{*}{\multicolumn{2}{|c|}{ Límites }} & $\mathrm{ppm}$ & $\mathrm{ppm}$ & $\mathrm{ppm}$ & $\mathrm{ppm}$ & $\mathrm{ppm}$ & $\mathrm{ppm}$ & $\mathrm{ppm}$ & $\mathrm{ppm}$ & $\mathrm{ppm}$ & $\mathrm{ppm}$ & $\mathrm{ppm}$ & $\mathrm{ppm}$ & $\mathrm{ppm}$ & $\mathrm{ppm}$ & $\mathrm{ppm}$ & $\mathrm{ppm}$ & $(\mathrm{mg} / \mathrm{kg})$ & $(\mathrm{mg} / \mathrm{kg})$ & $(\mathrm{mg} / \mathrm{kg})$ & \\
\hline & & 0,1 & 0,01 & 0,01 & 0,01 & 0,01 & 0,01 & 0,01 & 0,01 & 0,01 & 0,01 & 0,01 & 0,01 & 2 & 0,1 & 0,1 & 0 & 2 & 2 & 8 & \\
\hline
\end{tabular}

El comportamiento general de las tres muestras es comparable con rocas generadas en ambientes de subducción por encima de la placa subducida (arco), con enriquecimiento en tierras raras livianas (LREE) de alrededor de doscientas veces el condrito, y empobrecimiento hacia las tierras raras pesadas (HREE) por encima de diez veces el condrito, con anomalía negativa de Eu, probablemente debido a fraccionamiento de la plagioclasa en el magma, lo que permite que $\mathrm{Eu}^{+3}$ cambie su estado de oxidación a $\mathrm{Eu}^{+2}$ (figura 9A). Las relaciones $\mathrm{Eu} / \mathrm{Eu}^{*}<1$ y $(\mathrm{La} / \mathrm{Sm})_{\mathrm{N}}>2$ evidencian un enriquecimiento de tierras raras ligeras (LREE) con relación a las HREE en todas las muestras (tabla 5), y notable nucleación previa de la plagioclasa.

El diagrama multielemental de tierras raras (Sun y McDonough, 1989) muestra empobrecimiento de los elementos inmóviles Nb, Sr, Zr y Ti, que puede corresponder a separación de fases minerales accesorias, como

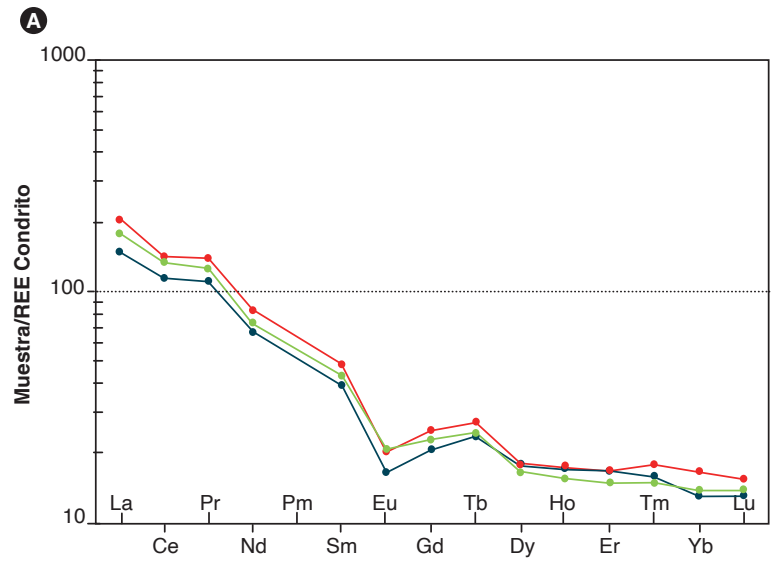

titanita, rutilo, circón y apatito, reflejo de la evolución magmática (Winter, 2001), donde el Nb se comporta geoquímicamente de manera similar al Ti (figura 9B). Los mayores valores de los elementos litófilos de alto radio iónico (LILE) Cs, Ba y Th indican una afinidad de corteza continental (márgenes convergentes), donde abundan estos elementos altamente incompatibles. Valores mayores en K, Ba y Rb se deben a su movilización desde fluidos que interactúan en la zona de subducción hacia el magma (figura 9B), y las anomalías negativas de $\mathrm{Nb}$ y Ti son características de arcos magmáticos relacionados con ambientes de subducción, con empobrecimiento progresivo hacia los elementos pesados. Además, presentan anomalía negativa de $\mathrm{Nb}$ con respecto al Th y Ce, que es la firma geoquímica típica de magmas originados en ambientes tectónicos relacionados con arcos, con patrón subparalelo en la mayoría de las muestras en cada grupo de rocas.

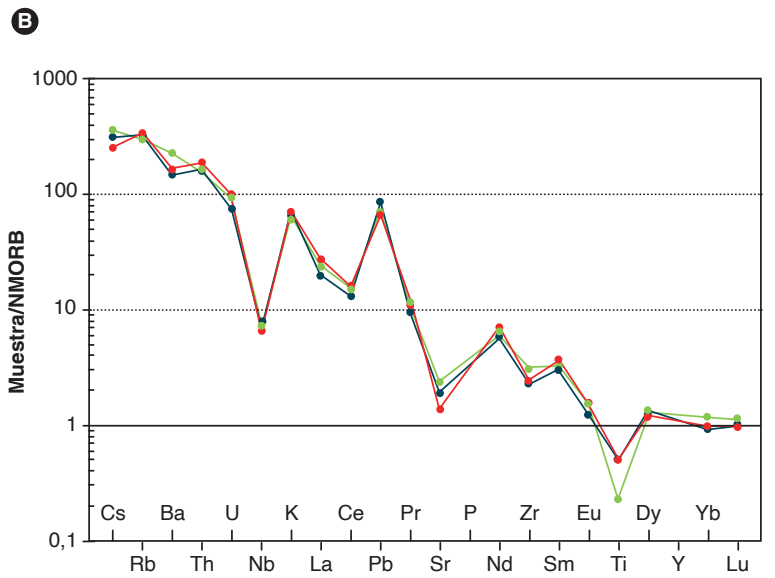

Figura 9. A) Diagrama de REE normalizado respecto al condrito (Nakamura, 1974). B) Diagrama multielemental normalizado al NMORB (Sun y McDonough, 1989) 
Tabla 5. Valores normalizados de REE según el condrito de Nakamura (1974) correspondientes a rocas de la Riolita de San Joaquín

\begin{tabular}{cccccccc}
\hline Muestra & Eu/Eu* & LaN/YbN & LaN/SmN & CeN/YbN & CeN/SmN & EuN/YbN & Suma_REE \\
\hline 900890 & 0,58 & 8,93 & 3,77 & 6,83 & 2,89 & 0,99 & 232,69 \\
\hline 900891 & 0,58 & 15,71 & 4,24 & 10,86 & 2,93 & 1,55 & 291,01 \\
\hline 900892 & 0,66 & 12,89 & 4,14 & 9,64 & 2,1 & 1,5 \\
\hline
\end{tabular}

\subsection{Discriminación de ambiente tectónico}

Según los diagramas $\mathrm{Th} / \mathrm{Yb}$ vs. $\mathrm{Nb} / \mathrm{Yb}, \mathrm{Rb} / \mathrm{Zr}$ vs. $\mathrm{Nb}$ y $\mathrm{Rb} / \mathrm{Sr}$ vs. $\mathrm{SiO}_{2}$ (Harris et al., 1986; Martin, 1994; Pearce, 2008) (figura 10), las rocas de la Riolita de San Joaquín tienen como equivalentes intrusivos los granitos de arco magmático normal, donde la corteza continental pudo

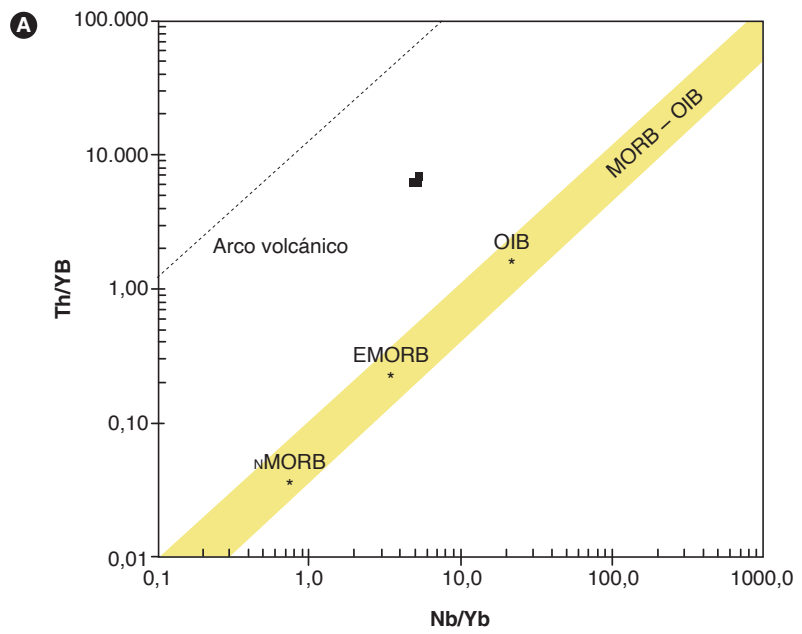

B

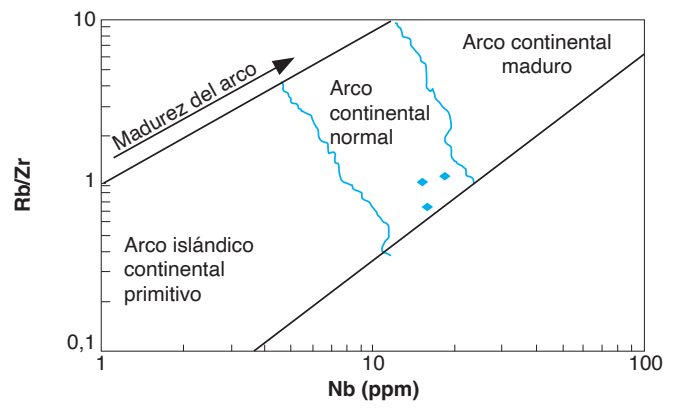

C

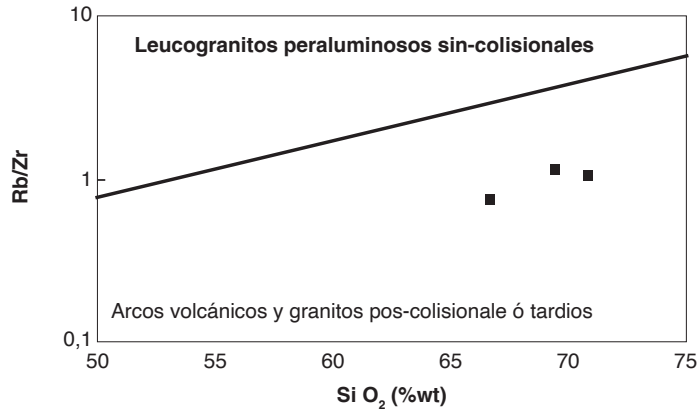

Figura 10. Gráficos de discriminación de ambiente geotectónico correspondientes a rocas de la Riolita de San Joaquín jugar un papel importante en la composición del magma. Además, los diagramas de elementos traza y REE (figura 9) exhiben anomalías negativas de $\mathrm{Ba}, \mathrm{Nb}$, Ti y $\mathrm{P}$, y anomalía positiva de $\mathrm{Pb}$. Este patrón es similar al de rocas generadas en un ambiente de arco.

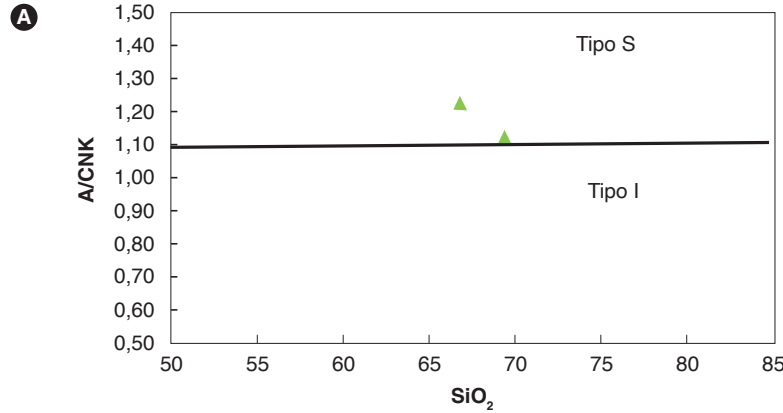

B

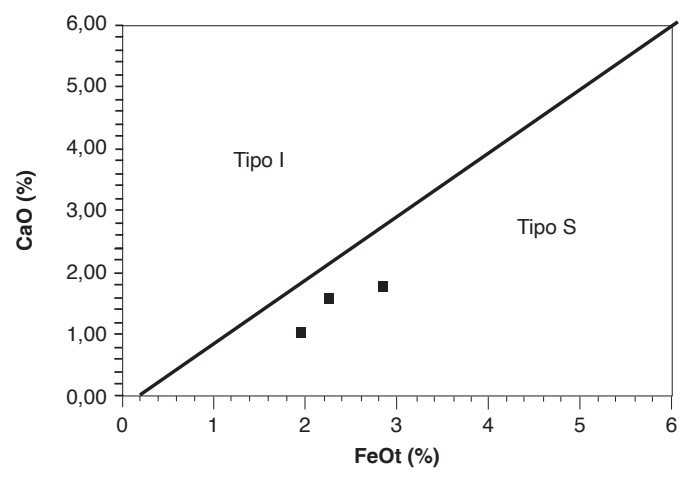

$\boldsymbol{\odot}$

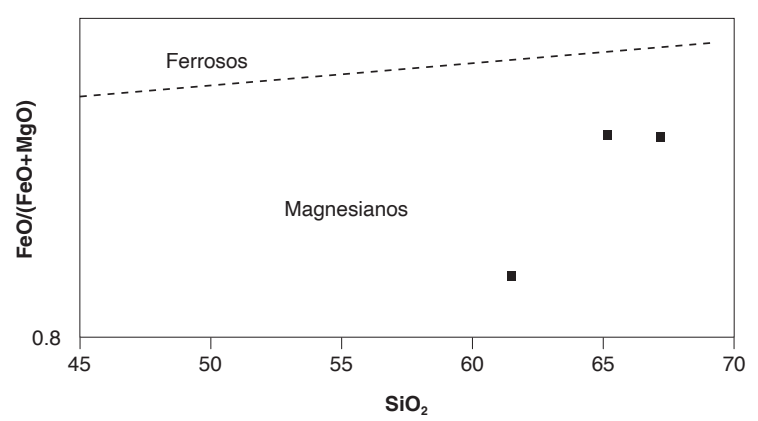

Figura 11. Diagramas de ambientes geotectónicos de la Riolita de San Joaquín 
Las rocas de la Riolita de San Joaquín se inscriben en el campo de los granitos tipo $\mathrm{S}$ en el diagrama A/CNKSiO2 de Frost et al. (2001) y en el gráfico de CaO vs. FeOt (modificado de Chappell y White, 2001) (figuras 11 A y B). En el diagrama de Frost et al. (2001) (figura 11 C) las muestras se localizan en el campo de magmas magnesianos, que presentan una composición general calcoalcalina en rocas de composición riolítica de afinidad peraluminosa, que presentan patrón de REE vs. el condrito de Nakamura (1974) y de tierras raras vs. NMORB, que las asocia a un ambiente de arco de margen continental. Según Frost y Frost (2008), los granitos tipo S se relacionan con un origen derivado de la fusión parcial de la corteza continental bajo condiciones oxidantes. Otros granitoides del Triásico y Jurásico del Macizo de Santander muestran una considerable herencia de núcleos y xenocristales de circones que indican un aporte cortical sobre las unidades metamórficas en las que se encajaron, como es el caso del Monzogranito de La Corcova (Rodríguez et al., 2016).

\section{Posición estratigráfica y edad}

La Riolita de San Joaquín se emplazó en el Neis de Bucaramanga; al suroeste está en contacto fallado con la Riolita del Alto de Los Cacaos y está intruida por el Batolito de Mogotes; en el extremo norte aparece en contacto con esquistos cuarzo-sericíticos, probablemente de la Formación Silgará, sobre los cuales reposa un cuerpo pequeño de areniscas de posible edad cretácica; además, se encuentra atravesada por diques y pequeños cuerpos de monzogranitos aplíticos.

En este trabajo se realizó la datación de la muestra GR-6729 (IGM-900890). Los resultados y localización de la datación se presentan en la figura 1, y las coordenadas se pueden consultar en la tabla 3.

La separación de minerales densos se realizó en el Laboratorio Químico del Servicio Geológico Colombiano, sede Medellín, utilizando separación hidrodinámica, magnética $y$, por último, el montaje de los circones sobre una cinta de doble faz pegada a un vidrio de $5 \times 5 \mathrm{~cm}$. La muestra GR-6729 fue enviada al Laboratorio de Estudios Isotópicos (LEI) del Centro de Geociencias de la Universidad Nacional Autónoma de México (UNAM), campus Juriquilla, donde se analizó con la siguiente metodología: las concentraciones de U y Th fueron calculadas empleando un circón estándar externo, de acuerdo con Paton et al. (2010). Las incertidumbres de sigma 2 propagadas se lograron según Paton et al. (2010). Las proporciones ${ }^{207} \mathrm{~Pb} /{ }^{206} \mathrm{~Pb}$, edades y errores se calcularon según Petrus y Kamber (2012). Los puntos estudiados son de 23 micrómetros, y se analizaron utilizando un protocolo modificado de Solari et al. (2010). Los datos se midieron empleando un Thermo X series QICPMS acoplado a un Resonetics, estación de trabajo láser Excimer Resolución M050. Se realizó un análisis estadístico con el fin de mejorar el rango de confiabilidad de la edad proporcionada por el laboratorio, teniendo en cuenta la relación $\left[\left({ }^{207} \mathrm{~Pb} /{ }^{235} \mathrm{U}\right)-\left({ }^{206} \mathrm{~Pb} /{ }^{238} \mathrm{U}\right) /{ }^{206} \mathrm{~Pb} /{ }^{238} \mathrm{U}\right)$, eliminando los datos de circones con valores discordantes que estuvieran, en general, por encima del 15\%, y errores de más del $5,5 \%$, trabajando en la muestra GR-6729 con $n=24$ de un total de 35 circones (anexo A).

Los gráficos de concordia e histogramas se elaboraron en el software de Isoplot/Ex vers. 4,15 (Ludwig, 2008) (figura 12).

Los circones de las muestras GR-6729 son euhedrales a subhedrales, prismáticos, alargados, tabulares, con forma de tallos, de tamaño variable, con una morfología entre acicular y corta prismática. En catodoluminiscencia (CL) muestran zonamientos concéntricos, así como bordes luminiscentes, algunos de ellos. Los análisis realizados arrojan edades concordantes de ca. $200 \mathrm{Ma}$ (figura 12B), con algunos cristales heredados del Paleozoico inferior (390 Ma n=1; 446,2 Ma (n=1)) (figura 12A), del Neoproterozoico (874 Ma, $\mathrm{n}=1$ ) concordante y del Proterozoico (1 630, $\mathrm{n}=1$ discordante).

La muestra GR-6729 se localiza en el sur del cuerpo. Las edades varían entre 191 y $209 \mathrm{Ma}$, con una edad promedio ponderada de $201,0 \pm 2,1$, con un $\mathrm{MSWD}=3,2$, edad que se interpreta como la de cristalización de esta roca (figura 12C).

Las razones $\mathrm{Th} / \mathrm{U}$ de los circones de la muestra GR6729 son mayores de 0,1, y están alrededor de 1 en aquellos circones que definen la edad promedio ponderada, relación que sugiere cristalización ígnea (Rubatto, 2002). Los circones heredados tienen razones $\mathrm{Th} / \mathrm{U}>0,1$, y probablemente son magmáticos (figura 12D).

\subsection{Geoquímica de elementos traza en circones}

El análisis de ICP-MS permitió determinar la abundancia de los elementos traza de cada circón de la muestra GR-6729 (tabla 6). Los valores de REE se normalizaron al condrito (McDonough y Sun, 1995) y se calcularon las relaciones $\mathrm{Pm}^{*}$ y Tm* en cada uno de ellos. En la figura 13 se observa un comportamiento paralelo y homogéneo en la mayoría de circones con edades entre 191 y 
209 Ma, con un patrón de REE con anomalía positiva de Ce y negativa de Eu poco pronunciada, semejante a la de granitos tipo I (figura 13), y tres circones que cruzan el patrón general con menor anomalía de Ce (Zr-26, Zr-28

(4)

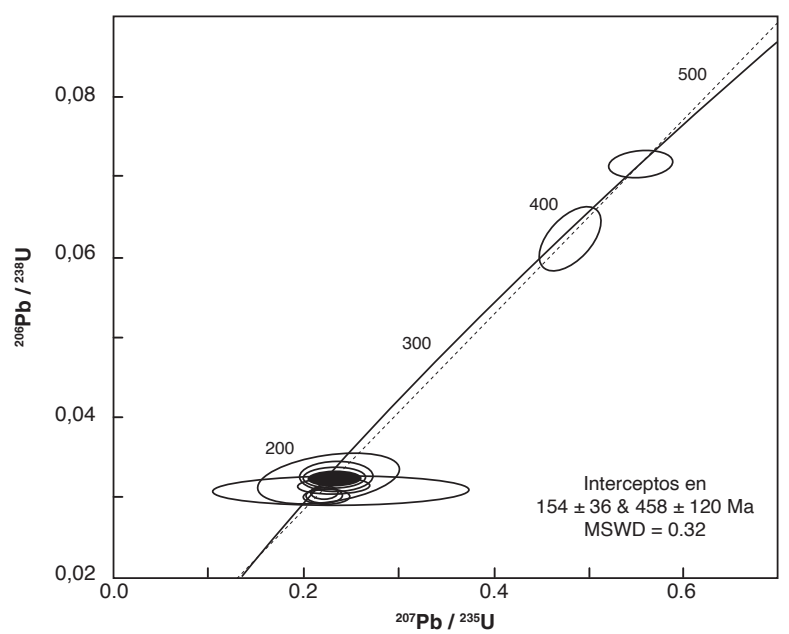

C

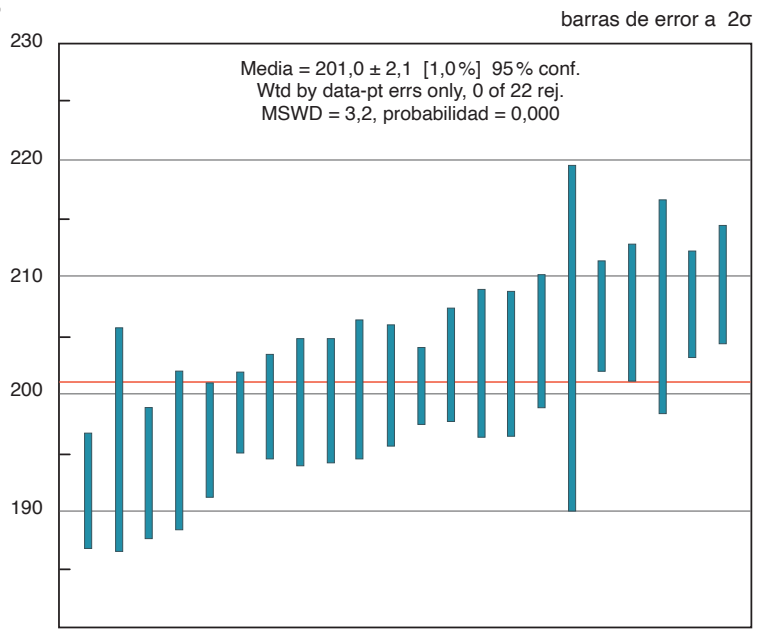

y Zr-29). Los circones que arrojaron edades del Paleozoico muestran anomalía positiva de Ce y negativa poco pronunciada de Eu, con la anomalía positiva de Ce alta.

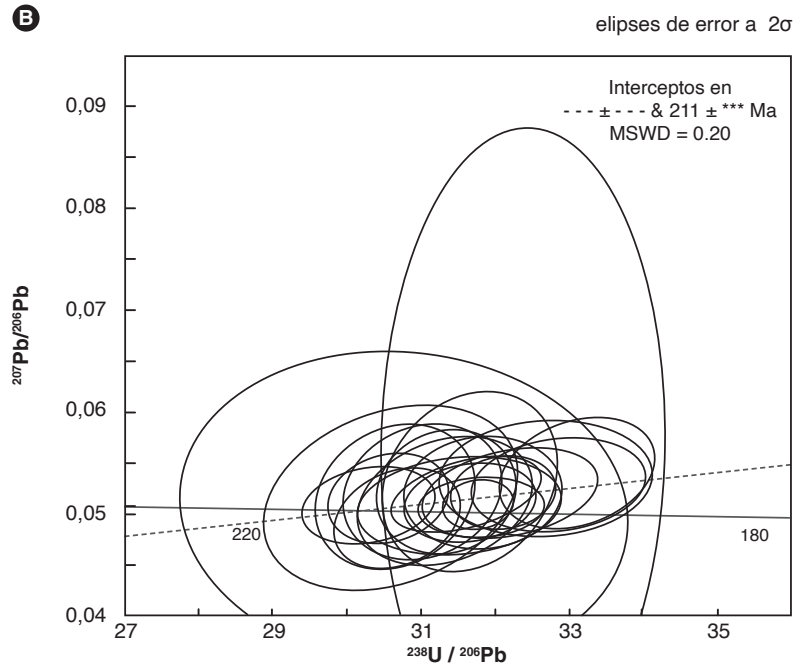

D

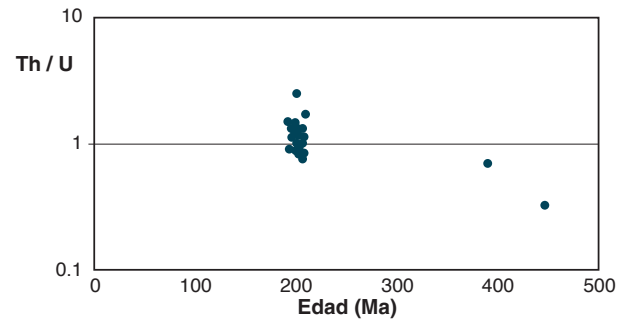

Figura 12. Muestra GR-6729: A) gráfico de concordia, B) gráfico Tera-Wasserburg, C) edad promedio ponderada y D) gráfico de la relación Th/U vs. edad

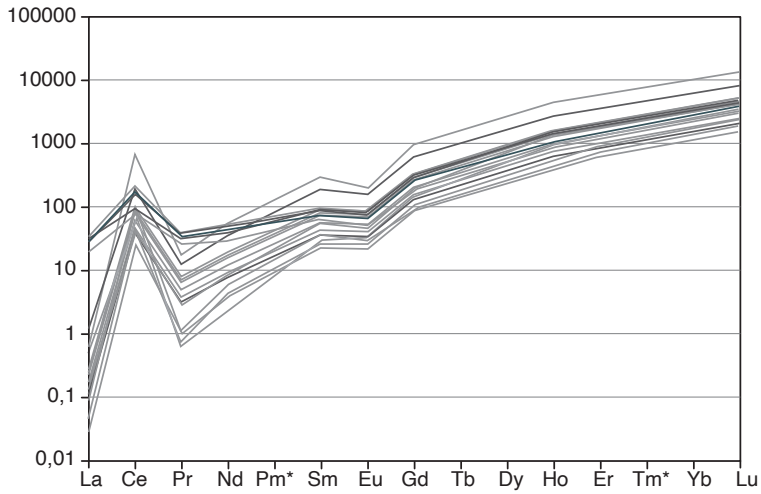

Figura 13. Patrones de los elementos de las tierras raras REE normalizados según el condrito de McDonough y Sun (1995) en circones de la muestra GR-6729 
Para discriminar entre granitoides de tipos I, A y S, Wang et al. (2012) consideran las diferencias en los contenidos de $\mathrm{Pb}$ y Th en circones. Los valores de $\mathrm{Pb}$ obtenidos en los circones de la muestra GR-6729 están entre 2,1 y 11,3 ppm; los de Th, entre 50,6 y 590 ppm; la rela- ción Th/Pb está entre 24,2 y 44; las concentraciones de Y (620-2.560 ppm) son parcialmente comparables a las de circones de granitoides (500-4.534), y los valores de $(\mathrm{Lu})_{\mathrm{N}}$ se encuentran entre 1.967 y 8.170 (normalizado al condrito de Sun y McDonough, 1989).

Tabla 6. Elementos traza de cada circón de la muestra GR-6729

\begin{tabular}{|c|c|c|c|c|c|c|c|c|c|c|c|c|c|c|c|c|c|c|c|c|c|}
\hline (ppm) & $\mathbf{P}$ & $\mathrm{Ti}$ & $\mathbf{Y}$ & $\mathrm{Nb}$ & La & $\mathrm{Ce}$ & $\mathrm{Pr}$ & $\mathrm{Nd}$ & $\mathrm{Sm}$ & $\mathrm{Eu}$ & Gd & Tb & Dy & Ho & $\mathrm{Er}$ & $\mathrm{Yb}$ & Lu & Hf & $\mathrm{Pb}$ & Th & $U$ \\
\hline Circón-003 & -3.400 & 9,4 & 510 & 1,4 & 0 & 17 & 0 & 1,3 & 2,5 & 0,5 & 12 & 4 & 50 & 17 & 74 & 149 & 30 & 6.600 & 10 & 38 & 56 \\
\hline Circón-004 & -710 & 9,9 & 311 & 2,1 & 0,2 & 13 & 0,1 & 0,8 & 1 & 0,4 & 5,4 & 2,2 & 28 & 11 & 49 & 107 & 23 & 6.400 & 1,7 & 33,1 & 46 \\
\hline Circón-011 & -3.200 & 93 & 1.290 & 10 & 0,1 & 44 & 0,1 & 2,1 & 4,5 & 1,3 & 27 & 9,6 & 117 & 46 & 206 & 391 & 80 & 9.000 & 8,4 & 186 & 256 \\
\hline Circón-013 & -4.300 & 10 & 1.670 & 6 & 0,4 & 49 & 0,5 & 3,5 & 5,8 & 1,9 & 35 & 12 & 151 & 59 & 263 & 500 & 101 & 11.100 & 9,5 & 223 & 330 \\
\hline Circón-016 & -2.000 & 17 & 1.050 & 2,7 & 0 & 26 & 0,1 & 2 & 3,6 & 1,4 & 20 & 6,8 & 86 & 35 & 159 & 336 & 71 & 10.100 & 2,5 & 77 & 85 \\
\hline Circón-017 & -2.300 & 15 & 1.540 & 3,8 & 0,1 & 38 & 0,2 & 3,4 & 5,8 & 2,3 & 33 & 11 & 137 & 53 & 239 & 460 & 97 & 7.400 & 3,6 & 149 & 117 \\
\hline Circón-022 & 600 & 9,4 & 940 & 1,2 & 0,5 & 20 & 0,3 & 3,7 & 6,2 & 1,7 & 28 & 8,2 & 87 & 33 & 140 & 250 & 54 & 6.100 & 1,8 & 76 & 53 \\
\hline Circón-023 & -1.100 & 23 & 2.670 & 4,2 & 0,7 & 55 & 0,9 & 12 & 20 & 7,2 & 84 & 25 & 242 & 96 & 363 & 630 & 137 & 8.800 & 5,9 & 279 & 166 \\
\hline Circón-024 & -10.500 & 11 & 1.640 & 8,4 & 0,3 & 29 & 0,1 & 1,3 & 3,1 & 0,7 & 24 & 9,8 & 135 & 57 & 260 & 505 & 105 & 9.900 & 18 & 233 & 483 \\
\hline Circón-030 & -10.300 & 8,3 & 1.310 & 7,3 & 1,2 & 51 & 0,6 & 7,1 & 8,3 & 2,8 & 38 & 12 & 133 & 50 & 196 & 375 & 74 & 8.600 & 6,9 & 203 & 196 \\
\hline Circón-033 & $-1 \mathrm{E}+06$ & 11 & 1.350 & 3,4 & 138 & 98 & 39 & 143 & 40 & 8,9 & 59 & 14 & 140 & 47 & 199 & 380 & 80 & 8.400 & 6,7 & 690 & 201 \\
\hline Circón-002 & -3.100 & 13 & 1.470 & 3,9 & 1 & 46 & 0,6 & 5,9 & 7,3 & 2,4 & 37 & 12 & 138 & 51 & 222 & 416 & 85 & 6.900 & 4,1 & 184 & 131 \\
\hline Circón-005 & -1.900 & 6,8 & 1.300 & 5,9 & 0 & 40 & 0,1 & 1,2 & 4,6 & 1,4 & 27 & 9,7 & 111 & 47 & 202 & 391 & 78 & 8.000 & 6 & 146 & 191 \\
\hline Circón-006 & -1.100 & 18 & 2.270 & 2,3 & 0,5 & 33 & 0,8 & 10 & 15 & 4,9 & 58 & 20 & 228 & 81 & 344 & 610 & 123 & 9.300 & 4,3 & 198 & 133 \\
\hline Circón-007 & -1.000 & 13 & 1.460 & 7,4 & 0,1 & 69 & 0,1 & 2,8 & 5,6 & 1,6 & 28 & 11 & 128 & 50 & 230 & 460 & 96 & 14.300 & 9,8 & 270 & 300 \\
\hline Circón-008 & -1.200 & 18 & 2.280 & 4,3 & 0 & 52 & 0,4 & 7,1 & 15 & 4,1 & 55 & 18 & 210 & 80 & 340 & 640 & 133 & 10.400 & 5,9 & 240 & 178 \\
\hline Circón-009 & -4.700 & 14 & 2.190 & 5,9 & 0 & 65 & 0,3 & 5,4 & 9,8 & 3,7 & 54 & 18 & 207 & 77 & 330 & 600 & 120 & 10.800 & 6,8 & 271 & 234 \\
\hline Circón-010 & -8.200 & 17 & 2.160 & 12 & 8,3 & 137 & 3,7 & 19 & 11 & 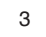 & 59 & 17 & 203 & 78 & 340 & 650 & 129 & 12.400 & 18 & 770 & 520 \\
\hline Circón-012 & -2.100 & 17 & 620 & 1,3 & 0 & 17 & 0,1 & 1,7 & 3,4 & 1,3 & 17 & 5,8 & 65 & 22 & 100 & 181 & 37 & 7.900 & 1,5 & 50,6 & 44 \\
\hline Circón-014 & -5.700 & 9,1 & 2.060 & 8 & 0,3 & 77 & 0,3 & 4 & 8,4 & 2,6 & 48 & 16 & 193 & 74 & 320 & 560 & 115 & 10.500 & 10 & 400 & 310 \\
\hline Circón-015 & -5.100 & 15 & 1.630 & 2,5 & 4,6 & 49 & 2,2 & 16 & 14 & 4,4 & 55 & 16 & 171 & 58 & 234 & 390 & 77 & 6.800 & 4,5 & 184 & 135 \\
\hline Circón-018 & -4.800 & 22 & 2.600 & 5 & 0,1 & 69 & 0,7 & 8,3 & 15 & 4,8 & 72 & 21 & 250 & 92 & 390 & 700 & 139 & 10.800 & 6,3 & 300 & 194 \\
\hline Circón-019 & -7.300 & 13 & 4.100 & 6,6 & 0,3 & 122 & 1,2 & 16 & 2 & 8,9 & 124 & 38 & 420 & 146 & 590 & 1.020 & 201 & 700 & 11 & 590 & 335 \\
\hline Circón-020 & -3.300 & 12 & 2.550 & 4,5 & 1,6 & 71 & 0,9 & 10 & 15 & 5,3 & 71 & 23 & 254 & 93 & 380 & 670 & 132 & 11.400 & 8,5 & 339 & 250 \\
\hline Circón-021 & -3.100 & 16 & 970 & 2,1 & 0 & 21 & 0,1 & 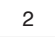 & 4,3 & 1,8 & 23 & 7,6 & 9 & 34 & 154 & 285 & 58 & 8.200 & 2,1 & 66 & 64 \\
\hline Circón-025 & -1.100 & 10 & 1.000 & 2,7 & 0,4 & 27 & 0,3 & 1,9 & 4 & 1,2 & 20 & 7 & 87 & 33 & 152 & 309 & 61 & 8.200 & 3,6 & 107 & 116 \\
\hline Circón-026 & -14.200 & 14 & 1.340 & 2,6 & 7,3 & 56 & 2,5 & 14 & 9,2 & 3,1 & 38 & 11 & 128 & 47 & 201 & 367 & 74 & 8.400 & 3,6 & 137 & 107 \\
\hline Circón-027 & -6.400 & 9,3 & 770 & 1,9 & 0 & 23 & 0,1 & 2,1 & 3,5 & 1,3 & 18 & 5,9 & 69 & 26 & 119 & 230 & 48 & 7.410 & 2,8 & 86 & 82 \\
\hline Circón-028 & -25.000 & 26 & 1.830 & 8,2 & 8,3 & 59 & 3 & 19 & 8,7 & 2,6 & 39 & 14 & 167 & 64 & 290 & 510 & 103 & 9.700 & 12 & 290 & 340 \\
\hline Circón-029 & -22.000 & 13 & 2.270 & 5,5 & 7,1 & 101 & 3,3 & 23 & 14 & 3,7 & 55 & 18 & 211 & 81 & 340 & 610 & 124 & 9.200 & 8,2 & 297 & 260 \\
\hline Circón-031 & -12.000 & 12 & 930 & 2,8 & 0 & 30 & 0,1 & 2 & 3,9 & 1,5 & 21 & 7,3 & 83 & 29 & 144 & 278 & 59 & 7.100 & 2,6 & 82 & 87 \\
\hline Circón-032 & $-1 E+05$ & 11 & 6.610 & 26 & 0,2 & 399 & 1,6 & 26 & 44 & 11 & 186 & 58 & 645 & 236 & 980 & 1.710 & 328 & 7.180 & 41 & 3.220 & 1.260 \\
\hline Circón-034 & 380.000 & 9,1 & 1.690 & 4,7 & 0 & 7,1 & 0,1 & 2,1 & 6,7 & 0,9 & 34 & 13 & 148 & 56 & 242 & 450 & 90 & 10.500 & 27 & 118 & 354 \\
\hline Circón-035 & 24.000 & 12 & 1.940 & 7,9 & 0,5 & 31 & 0,4 & 4,1 & 7,6 & 2 & 43 & 15 & 178 & 68 & 289 & 510 & 104 & 10.500 & 39 & 452 & 640 \\
\hline
\end{tabular}

Los granitos de tipo I, según Wang et al. (2012), presentan contenidos de $\mathrm{Pb}<25 \mathrm{ppm}$, Th entre 34 y 1.746 $\mathrm{ppm}, \mathrm{Th} / \mathrm{Pb}$ de 14 a $130,(\mathrm{Lu})_{\mathrm{N}}$ entre 1.330 y $5.574, \mathrm{y}$ concentraciones de Y entre 493 y 7.833 ppm. Los granitos de tipo S, según Wang et al. (2012), presentan contenidos de $\mathrm{Pb}$ de 4 a $161 \mathrm{ppm}$, Th de 25 a 1.183 ppm (principalmente entre 30 y $700 \mathrm{ppm}$ ), relaciones $\mathrm{Th} / \mathrm{Pb}$ entre (0,4 y 21), concentraciones de Nb entre 1 y 5 ppm, comparable con las de circones de granitos tipo I. El $(\mathrm{Lu})_{\mathrm{N}}$ varía entre 609 y 7.376, Y de 214 a 5.503 ppm.

Al comparar los valores de elementos traza en circones con los valores propuestos por Wang et al. (2012) para granitoides de tipos I y $\mathrm{S}$, no se distingue con claridad el tipo de granito al que corresponde la Riolita de San Joaquín, lo que puede deberse al avanzado grado de fraccionamiento de los granitos (monzogranitos y sieno- 
granitos), ya que, según Wang et al. (2012), hay dificultad para distinguir, a partir de los elementos traza en circones, entre los granitos tipos I y $S$ altamente evolucionados.

\section{Correlaciones}

La Riolita de San Joaquín hace parte del magmatismo ocurrido entre el Triásico y el Jurásico, que se emplazó en el basamento metamórfico del Macizo de Santander y cuya correlación se extiende tanto a los cuerpos subvolcánicos porfídicos como a cuerpos plutónicos de composición granítica, entre los que se encuentra el Monzogranito de La Corcova, la Tonalita y Granodiorita de Páramo Rico, el Batolito de Mogotes, el Granito de Pescadero, el Monzogranito de Rionegro y pequeños plutones subvolcánicos como la Riolita de El Uvo.

Al comparar la edad de la Riolita de San Joaquín y las edades de diques y cuerpos menores asociados a otros plutones triásico-jurásicos del Macizo de Santander, al menos por edad, este cuerpo es comparable con algunos de los pulsos de los otros plutones.

Al comparar la clasificación química de las rocas de la Riolita de San Joaquín con la clasificación química de las rocas de las Riolitas El Uvo y la Riolita del Alto de Los Cacaos (figura 14A), que serían las unidades más próximas y correlacionables, se encuentran algunas diferencias: las rocas de la Riolita de San Joaquín pertenecen al campo de las riodacitas, mientras las rocas de El Uvo y Los Cacaos se inscriben en el campo de las riolitas (en el diagrama de Winchester y Floyd, 1977). En el diagrama multielemental normalizado al condrito de Nakamura (1974) se observa que los patrones de las REE se separan entre los cuerpos de riolita, y en algunos casos se cruzan localmente (figura 14B). Además, en las rocas de la Riolita de San Joaquín, la $\Sigma$ varía entre 232 y $291>\sum$ Riolita de Los Cacaos (1 24 a 146) > ¿ Riolita de El Uvo (86 a 96).

La edad de cristalización de las rocas de la Riolita de San Joaquín y de la Riolita del Alto de Los Cacaos es comparable, y es anterior a la de la Riolita de El Uvo, lo que sugiere que se trata de cuerpos de pórfidos generados en el mismo arco, a partir de diferentes pulsos magmáticos.

\section{Localidad tipo}

Se propone como sección tipo la carretera San Joaquín-vereda La Aurora, donde se puede observar la unidad y algunos de los contactos intrusivos con el Neis de Bucaramanga, en el sector de la Boca del Cedro.
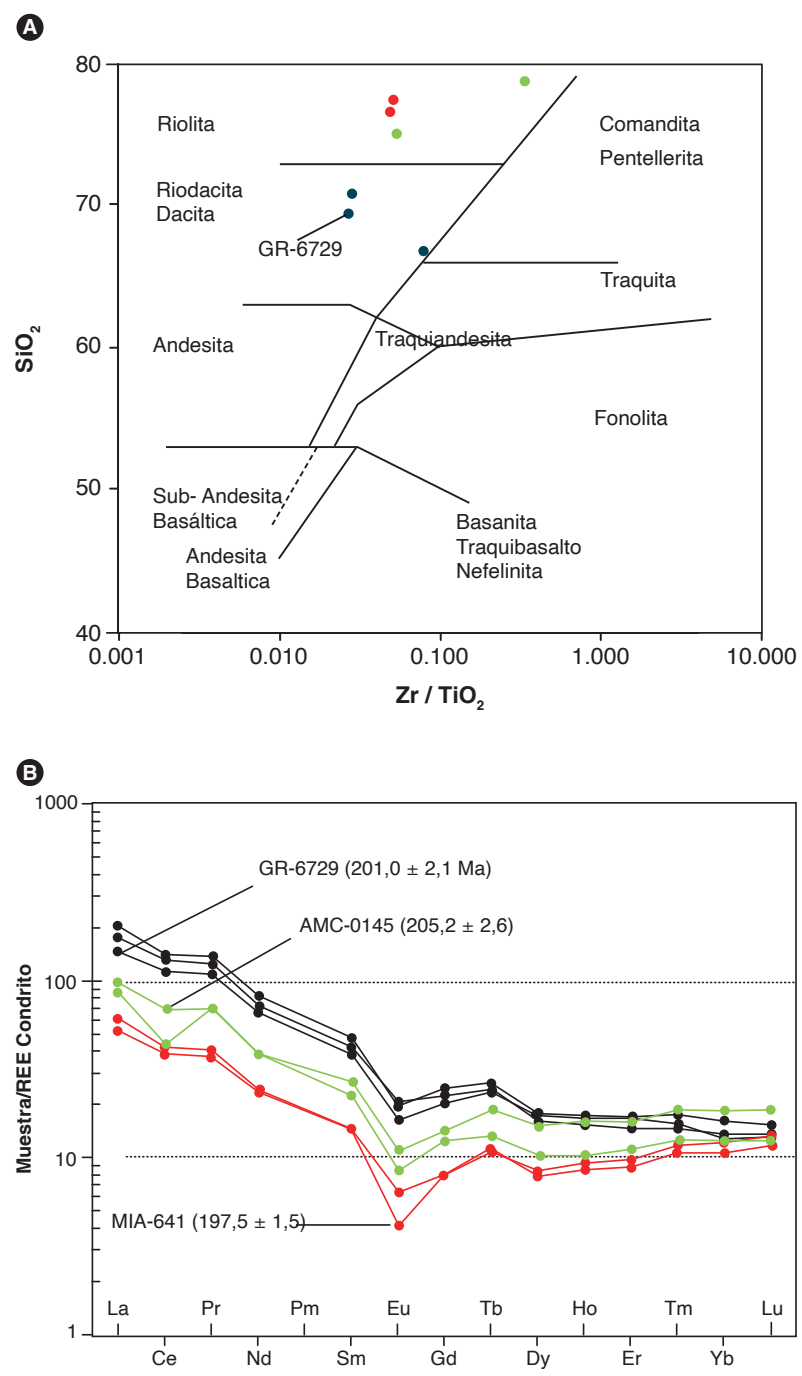

Figura 14. Comparación química de rocas de la Riolita de San Joaquín con rocas de la Riolita de El Uvo y del Alto de Los Cacaos Negro: Riolita de San Joaquín; rojo: Riolita de El Uvo; verde: Riolita del Alto Los Cacaos.

\section{Génesis}

Las características macroscópicas y microscópicas de la Riolita de San Joaquín, como textura porfídica y matriz microcristalina felsítica a micrográfica, evidencian un emplazamiento subvolcánico poco profundo del cuerpo, que ocurrió en un basamento metamórfico (Neis de Bucaramanga).

Dicha riolita presenta valores de $\mathrm{SiO}_{2}$ entre $65,40 \%$ y $69,6 \%$, que corresponde a rocas ácidas, con alto contenido de álcalis $\left(\mathrm{Na}_{2} \mathrm{O}+\mathrm{K}_{2} \mathrm{O}\right.$ entre 7,4 y 8,7\%); relación $\mathrm{K}_{2} \mathrm{O}$ / $\mathrm{Na}_{2} \mathrm{O}$ entre 0,48 y $1,04, \mathrm{y} \mathrm{Al}_{2} \mathrm{O}_{3}>\mathrm{CaO}+\mathrm{Na}_{2} \mathrm{O}+\mathrm{K}_{2} \mathrm{O}$, de la serie calcoalcalina alta en $\mathrm{K}$; grafica en el campo peraluminoso, lo que sugiere aporte al magma de material de cor- 
teza continental. Muestra un enriquecimiento en tierras raras livianas (LREE) de más de cien veces el valor del condrito, si bien se va empobreciendo progresivamente hacia las tierras raras pesadas (HREE); además, presenta un comportamiento normal en rocas generadas en ambientes de subducción (arco).

La Riolita de San Joaquín muestra anomalías negativas y empobrecimiento de los elementos inmóviles $\mathrm{Nb}$, Sr, Zr, Ti. Los mayores valores de los elementos litófilos de alto radio iónico (LILE) Cs, Ba y Th indican una afinidad de corteza continental (márgenes convergentes). Las anomalías negativas de Nb y Ti son características de arcos magmáticos relacionados con ambientes de subducción.

Las rocas de la Riolita de San Joaquín son granitos tipo S, que, de acuerdo con Frost y Frost (2008), se relacionan con un origen derivado de la fusión parcial de la corteza continental en condiciones oxidantes.

\section{Recursos minerales}

No se conocen mineralizaciones asociadas a la Riolita de San Joaquín. La alteración meteórica de este cuerpo intrusivo es profunda y desarrolla perfiles de suelo y saprolito espesos. La Riolita de San Joaquín presenta abundantes diaclasas y fracturas que hacen de este un cuerpo poco atractivo para explotarlo como piedra ornamental. Los saprolitos arenosos formados a partir de la Riolita de San Joaquín son útiles como material arenoso, pero este tipo de material abunda en otros cuerpos de los alrededores, como el Batolito de Mogotes, que tienen mejor acceso y son más cercanos a centros urbanos, lo que le resta importancia a este cuerpo intrusivo.

La unidad Riolita de San Joaquín no exhibe características petrográficas y geoquímicas que evidencien una alteración hidrotermal. Con el fin de evaluar el potencial mineral de la unidad, se interpretaron algunos datos químicos a partir de los resultados de química de roca total de tres muestras y de la química de los circones de la muestra datada por U/Pb (GR-6729), utilizando diagramas que son reconocidos como indicadores de fertilidad de las rocas. En el diagrama de Rb versus Ba (figura 15), adaptado por El-Sheshtawi et al. (1999) del diagrama original de Mason (1966), se aprecia que dos de las muestras de riolitas corresponden a rocas fértiles (GR-6729 y GR-6730, potencialmente mineralizadas), mientras que la muestra GR-6731 grafica en el campo de las rocas no fértiles.

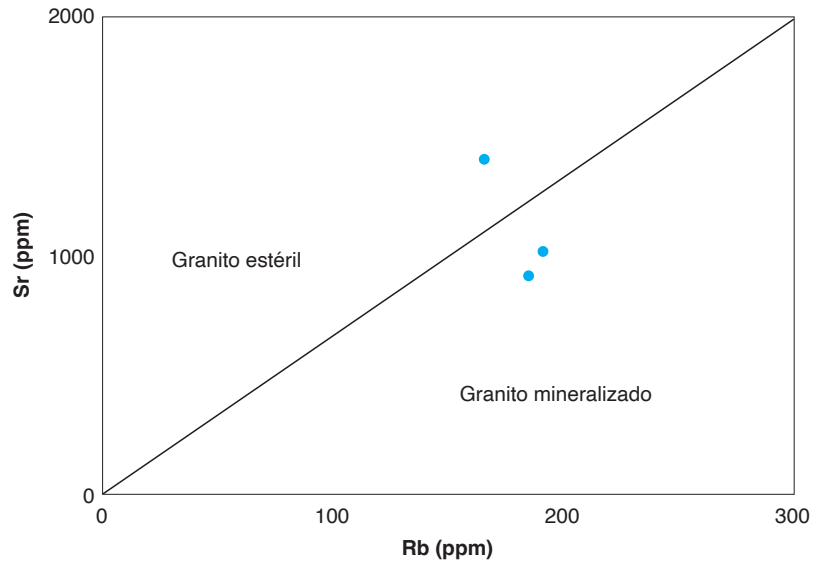

Figura 15. Diagrama de variación de Rb versus Ba (Mason, 1966 adaptado por El-Sheshtawi et al., 1999)

La composición de los circones permite distinguir entre suites magmáticas fértiles e infértiles, siendo la relación $\mathrm{Eu} / \mathrm{Eu}^{*}$ uno de los mejores indicadores de fertilidad. Específicamente, cuando esta relación es mayor de 0,3 , indica una roca potencialmente fértil ( $\mathrm{Lu}$ et al., 2016 ). Según el diagrama (Ce/Nd)/Y versus Eu/Eu* (figura 16), los circones de la muestra GR-6729 de la Riolita de San Joaquín grafican en el campo de suites fértiles de sistemas de pórfidos $\mathrm{Cu} \pm \mathrm{Mo} \pm \mathrm{Au}$.

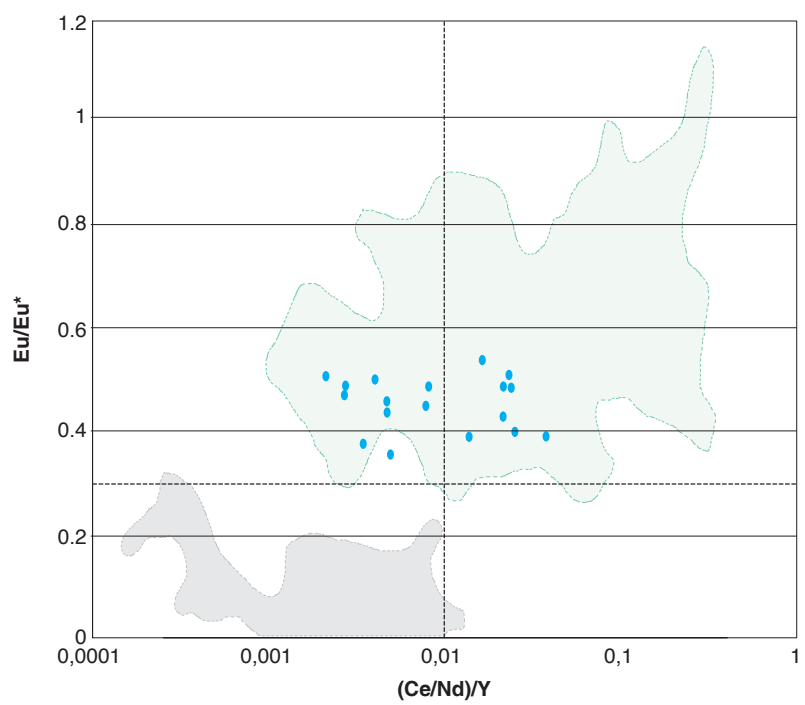

Figura 16. Composición de los circones de la Riolita de San Joaquín (muestra GR-6729), en diagrama de Lu et al. (2016), con campos de suites fértiles en verde claro, e infértiles, en gris. Los valores de normalización usados para calcular Eu/Eu* son los de Sun y McDonough (1989) 


\section{Conclusiones}

Este catálogo presenta un cuerpo intrusivo que no había sido relacionado en la bibliografía, e incorpora el conocimiento petrográfico, litogeoquímico y geocronológico al magmatismo del Triásico y Jurásico del Macizo de Santander.

Petrográficamente, las rocas de la Riolita de San Joaquín corresponden a riolita, dacita y andesita, presentan textura porfídica y matriz entre felsítica y micrográfica, constituida por fenocristales de plagioclasa, feldespato alcalino, cuarzo y biotita, y como minerales accesorios, opacos, apatito, circón y epidota.

Químicamente, muestra composición ácida con valores de $\mathrm{SiO}_{2}$ que varían entre $65,40 \%$ y 69,6\%; el K 2 O varía entre 4,3\% y 4,97\%; el CaO varía entre 1,03\% y 1,6\%, $\mathrm{MgO}<1 \%$ y $\mathrm{TiO}_{2}<0,65 \%$; el contenido de $\mathrm{Al}_{2} \mathrm{O}_{3}$ oscila entre $16,5 \%$ y $18,2 \%$; los valores de $\mathrm{Fe}_{2} \mathrm{O}_{3}$ son bajos, entre $2,13 \%$ y $3,10 \%$, acordes con el bajo contenido de minerales ferromagnesianos. Las rocas analizadas se clasifican como riolitas y traquidacitas en el diagrama TAS, y como riodacitas en el diagrama de Winchester y Floyd (1977).

La Riolita de San Joaquín corresponde a un plutón peraluminoso con valores de $\mathrm{A} / \mathrm{NK}>1 \mathrm{y}$ valores de $\mathrm{A} /$ $\mathrm{CNK}>1$, con valores de $\mathrm{Al}_{2} \mathrm{O}_{3}>\mathrm{CaO}+\mathrm{Na}_{2} \mathrm{O}+\mathrm{K}_{2} \mathrm{O}$; subalcalino, de la serie calcoalcalina alta en $\mathrm{K}$ y shoshonítica. En general, la tendencia corresponde a rocas generadas en ambientes de subducción por encima de la placa subducida (arco).

Según la química de roca total, la Riolita de San Joaquín se clasifica como un granito tipo $S$ formado en un ambiente de arco continental. Las características mineralógicas, como feldespato alcalino de color rosado, biotita parda y altos contenidos de $\mathrm{Na}_{2} \mathrm{O}$, junto con la química del circón, sugieren que es un granito tipo I.

Se obtuvo una edad U/Pb en circones de 201, $0 \pm 2,1$ Ma (Rheatiano), que se interpreta como la edad de cristalización del plutón, con escasos núcleos heredados del Paleozoico inferior, $390 \mathrm{Ma}(\mathrm{n}=1)$; 446,2 $\mathrm{Ma}(\mathrm{n}=1)$, y del Neoproterozoico, $874 \mathrm{Ma}(\mathrm{n}=1)$, que sugieren aporte al magma del basamento metamórfico.

Se correlaciona con todos los batolitos del Triásico y del Jurásico del Macizo de Santander y con cuerpos hipoabisales, como la Riolita de El Uvo y la del Alto de Los Cacaos, pero debido a las diferencias químicas y edad, se considera formada a partir de un pulso diferente en el mismo arco.

\section{Referencias}

Chappell, B. W. y White, A. J. R. (2001). Two contrasting granite types: 25 years later. Australian Journal of Earth Sciences, 48 (4), 489-499. https://doi.org/10.1046/j.1440-0952.2001.00882.x

Clavijo, J. (1994). Mapa geológico generalizado del departamento de Norte de Santander. Memoria explicativa. Escala 1:250.000. Informe. Ingeominas.

Clavijo, J., Mantilla, F. L. C., Pinto, J., Bernal, L. y Pérez, A. (2008). Evolución geológica de la serranía de San Lucas, norte del valle medio del Magdalena y noroeste de la cordillera Oriental. Boletín de Geología, 30 (1), 45-62.

Debon, F. y Le Fort, P. (1983). A chemical mineralogical classification of common plutonic rocks and associations. Earth and Environmental Science Transactions of The Royal Society of Edinburgh, 73 (3), 153-149. https://doi.org/10.1017/S0263593300010117

El-Sheshtawi, Y. A., Youssef, F., Ammar, F. A., Hassaan, M. M. y Sakr, S. M. (1999). Petrography and geochemistry of some granites and their metavolcanic country rocks in the Central Eastern Desert, Egypt. The proceeding of 1 st Seminar of nuclear raw material and their technology. Cairo, Egypt, 1-3.

Etayo, F., Barrero, D., Lozano, H., Espinosa, A., González, H., Orrego, A., Ballesteros, I., Forero, H. y Ramírez, C. (1983). Mapa de terrenos geológicos de Colombia. Publicaciones Geológicas Especiales del Ingeominas, n. ${ }^{\circ} 14,235$.

Frost, B. R., y Frost, C. D. (2008). A geochemical classification for feldespathic igneous rocks. Journal of Petrology, 49 (11), 1955-1969. https://doi.org/10.1093/ petrology/egn054

Frost, R. B., Barnes, C. G., Collins, W. J., Arculus, R. J., Ellis, D. J. y Frost, C. D. (2001). A geochemical classification for granitic rocks. Journal of Petrology, 42 (1 1), 2033-2043. https://doi.org/1 0.1093/petrology/42.11.2033

García, C. y Ríos, C. (1999). Metamorfismo y metalogenia asociada del Macizo de Santander, cordillera Oriental, Colombia. Informe final, Proyecto de Investigación 1102-05-083-95. Colciencias y Universidad Industrial de Santander.

Harris, N. W., Pearce, J. A. y Tindle, A. (1986). Geochemical characteristics of collision zone magmatism. En M. P. Coward y A. C. Ries (eds.), Collision tectonics. 
Special publication n. ${ }^{\circ} 19$. Geological Society. https://doi.org/10.1144/GSL.SP.1986.019.01.04

Hastie, A. R., Kerr, A. C., Pearce, J. A. y Mitchell, S. F. (2007). Classification of altered volcanic island arc rocks using immobile trace elements: Development of the Th-Co discrimination diagram. Journal of Petrology, 48 (12), 2341-2357. https://doi. org/10.1093/petrology/egm062

International Subcommision on Stratigraphic Classification. (1987). Stratigraphic classification and nomenclature of igneous and metamorphic rock bodies. GSA Bulletin, 99 (3), 440-442. https://doi.org/10.1130/001 6-7606(1987)99<440:SCANOI >2.0. $\mathrm{CO} ; 2$

International Subcommision on Stratigraphic Classification. (1994). International Stratigraphic Guide: A guide to stratigraphic classification, terminology and procedure. Boulder: Geological Society of America. https://doi.org/10.1130/9780813774022

Irvine, T. N. y Baragar, W. R. A. (1971). A guide to the chemical classification of the common volcanic rock. Canadian Journal of Earth Sciences, 8 (5), 523548. https://doi.org/10.1139/e71-055

Janoušek, V., Farrow, C. M. y Erban, V. (2006). Interpretation of whole-rock geochemical data in igneous geochemistry: Introducing Geochemical Data Toolkit (GCDkit). Journal of Petrology, 47 (6), 1 255-1 259. https://doi.org/10.1093/petrology/egl013

Le Bas, M. J., Le Maitre, R. W., Streckeisen, A. y Zanettin, B. (1986). A chemical classification of volcanic rocks based on the total alkali-silica diagram. Journal of Petrology, 27 (3), 745-750. https://doi.org/10.1093/ petrology/27.3.745

Leal Mejía, H. (2011). Phanerozoic gold metallogeny in the Colombian Andes: A tectono- magmatic approach $[\mathrm{Ph}$. D. thesis]. Universitat de Barcelona.

Lu, Y. J., Loucks, R. R., Fiorentini, M., Mccuaig, T. C., Evans, N. J., Yang, Z. M., Hou, Z. Q., Kirkland, C. L., Parra Ávila, L. A. y Kobussen, A. (2016). Zircon compositions as a pathfinder for porphyry $\mathrm{Cu} \pm \mathrm{Mo} \pm \mathrm{Au}$ deposits. En Tectonics and Metallogeny of the Tethyan Orogenic Belt (pp. 329-347). Special publication vol. 19. Society of Economic Geologists.

Ludwig, K. R. (2008). Isoplot version 4.15: A geochronological toolkit for Microsoft Excel. Special Publication n. ${ }^{\circ}$ 4. Berkeley Geochronology Center.
Mantilla, L. C., Bissig, T., Valencia. V. y Hart, C. (2013). The magmatic history of the Vetas-California mining district, Santander Massif Eastern Cordillera, Colombia. Journal of South American Earth Sciences, 45, 235-249. https://doi.org/10.1016/j.jsames. 2013.03.006

Martin, H. (1994). Archean grey gneisses and the genesis of the continental crust. En K. Codie (ed.), Archean crustal evolution (pp. 205-260). Netherland: Elsevier Scientific Publishers.

Mason, B. (1966). Principles of geochemistry. New York: John Wileys \& Sons.

McDonough, W. F. y Sun S. S. (1995). The composition of the Earth. Chemical Geology, 120 (1-3), 223-253. https://doi.org/10.1016/0009-2541(94)00140-4

Nakamura, N. (1 974). Determination of REE, Ba, Fe, Mg, $\mathrm{Na}$ and $\mathrm{K}$ in carbonaceous and ordinary chondrites. Geochimica et Cosmochimica Acta, 38 (5), 757-775. https://doi.org/10.1016/001 6-7037(74)90149-5

Ordóñez Cardona, O., Restrepo Álvarez, J. J. y Pimentel, M. M. (2006). Geochronological and isotopical review of pre-Devonian crustal basement of the Colombian Andes. Journal of South American Earth Sciences, 21 (4), 372-382. https://doi.org/10.1016/j. jsames.2006.07.005

Paton, C., Woodhead, J. D., Hellstrom, J. C., Hergt, J. M., Greig, A. y Maas, R. (2010). Improved laser ablation $\mathrm{U} / \mathrm{Pb}$ zircon geochronology through robust downhole fractionation correction. Geochemistry Geophysics Geosystems, 11 (3). https://doi.org/10.1029/ 2009GC002618

Pearce, J. A. (2008). Geochemical fingerprinting of oceanic basalts with applications to ophiolite classification and the search for Archean oceanic crust. Lithos, 100 (1-4), 14-48. https://doi.org/10.1016/j. lithos.2007.06.016

Peccerillo, A. y Taylor, T. S. (1976). Geochemistry of Eocene calc-alkaline volcanic rocks from Kastamonu area, Northern Turkey. Contributions to Mineralogy and Petrology, 58 (1), 63-81. https://doi. org/10.1007/BF00384745

Petrus, J. A. y Kamber, B. S. (2012). VizualAge: A novel approach to laser ablation ICP-MS U/Pb geochronology data reduction. Geostandards and Geoanalytical Research, 36 (3), 247-270. https://doi.org/10.1111/ j.1 751-908X.2012.00158.x 
Restrepo, J. J. y Toussaint, J. F. (1988). Terranes and continental accretion in the Colombian Andes. Episodes, 11 (3), 189-193. https://doi.org/10.1 8814/epiiugs/1988/v1 1i3/006

Restrepo, J. J., Ordóñez Carmona, O., Armstrong, R. y Pimentel, M. M. (2011). Triassic metamorphism in the northern part of the Tahamí Terrane of the Central Cordillera of Colombia. Journal of South American Earth Sciences, 32 (4), 497-507. https:/doi.org/10.1016/j.jsames.2011.04.009

Ríos, C., García, C. y Takusa, A. (2003). Tectono-metamorphic evolution of the Silgara Formation metamorphic rocks in the Southwestern Santander Massif, Colombian Andes. Journal of South American Earth Sciences, 16 (2), 133-154. https:/doi. org/10.1016/S0895-9811(03)00025-7

Rodríguez, G., Correa, A. M., Zapata, G. y Arango, M. I. (2016). Catálogo de unidades litoestratigráficas de Colombia. Monzogranito de La Corcova. Medellín: Servicio Geológico Colombiano.

Rubatto, D. (2002). Zircon trace element geochemistry: Partitioning with garnet and the link between U/ $\mathrm{Pb}$ ages and metamorphism. Chemical Geology, 184 (1-2), 123-138. https://doi.org/10.1016/S00092541(01)00355-2

Shand, S. J. (1943). Eruptive rocks: Their genesis, composition, classification, and their relation to ore-deposits with a chapter on meteorite. New York: John Wiley \& Sons.

Smith, J. V. y Brown, W. L. (1988). Feldspar minerals. I. crystal structures, physical, chemical and microtextural properties. Berlin: Springer-Verlag. https://doi. org/10.1007/978-3-642-72594-4

Solari, L., Gómez Tuena, A., Bernal, J., Pérez Arvizu, O. y Tanner, M. (2010). U/Pb zircon geochronology with an integrated LA-ICP-MS microanalytical workstation: Achievements in precision and accuracy. Geostandards and Geoanalytical Research, 34 (1), 5-18. https://doi.org/10.1111/j.1751908X.2009.00027.x

Streckeisen, A. L. (1978). Classification and nomenclature of volcanic rocks, lamprophyres, carbonatites and melilite rocks: Recommendations and suggestions. Neues Jahrbuch für Mineralogie, Abhandlungen, 141, 1-14.
Sun, S. y Mcdonough, W. (1989). Chemical and isotopic systematics of oceanic basalts: Implications for mantle composition and processes. En A. Sanders y M. Norry (eds.), Magmatism in oceanic basins, vol. 42. Londres: The Geological Society. https://doi. org/10.1144/GSL.SP.1989.042.01.19

Van der Lelij, R. (2013). Reconstructing North-Western Gondwana with implications for the evolution of the lapetus and Rheic Oceans: A geochronological, thermochronological and geochemical study [Tesis de doctorado]. Université de Genéve.

Van der Lelij, R., Spikings, R. y Mora, A. (2016). Thermochronology and tectonics of the Mérida Andes and the Santander Massif, NW South America. Lithos, 248-251, 220-239. https://doi.org/10.1016/j. lithos.2016.01.006

Villaseca, C., Barbero, L. y Herreros. V. (1998). A reexamination of the typology of peraluminous granite types in intracontinental orogenic belts. Earth and Environmental Science Transactions of The Royal Society of Edinburgh, 89 (2), 113-119. https:/doi. org/10.1017/S0263593300007045

Wang, Q., Zhu, D. C., Zhao, Z. D., Guan, Q., Zhang, X. Q., Sui, Q. L., Chu Hu, Z. y Mo, X. X. (2012). Magmatic zircons from I-, S- and A-type granitoids in Tibet: Trace element characteristics and their application to detrital zircon provenance study. Journal of Asian Earth Sciences, 53, 59-66. https://doi.org/10.1016/j. jseaes.2011.07.027

Ward, D., Goldsmith, R., Cruz, J. y Restrepo, A. (1973). Geología de los cuadrángulos H-1 2 Bucaramanga y H-13 Pamplona, departamento de Santander. Boletín Geológico, 21 (1-3), 1-132.

Wilson, M. (1991). Igneous petrogénesis: A global tectonic approach. London: Harper Collins Academic.

Winchester, J. A. y Floyd, P. A. (1977). Geochemical discrimination of different magma series and their differentiation products using immobile elements. Chemical Geology, 20, 325-343. https:/doi. org/10.1016/0009-2541(77)90057-2

Winter, J. (2001). An introduction to igneous and metamorphic petrology. New Jersey: Prentice Hall. 


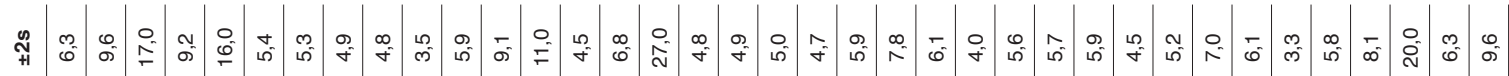

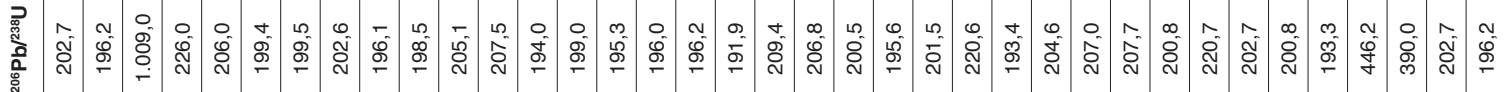

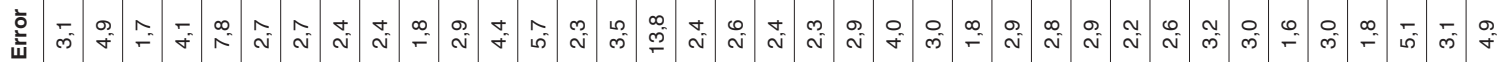

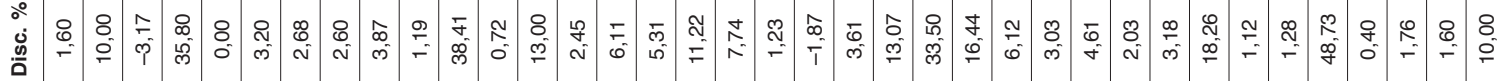

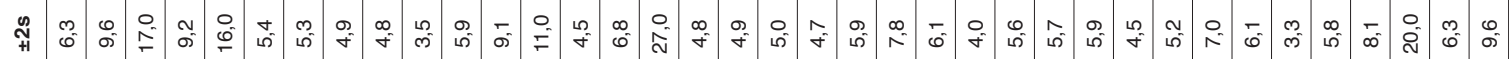

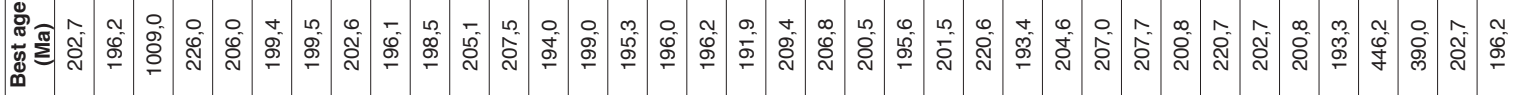

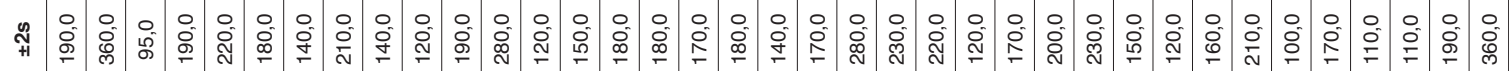

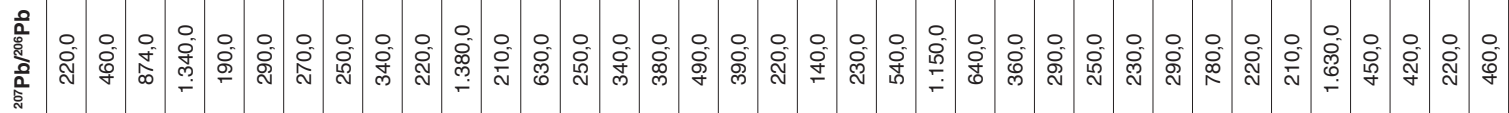
光

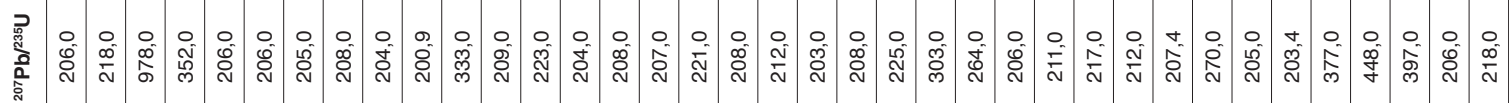

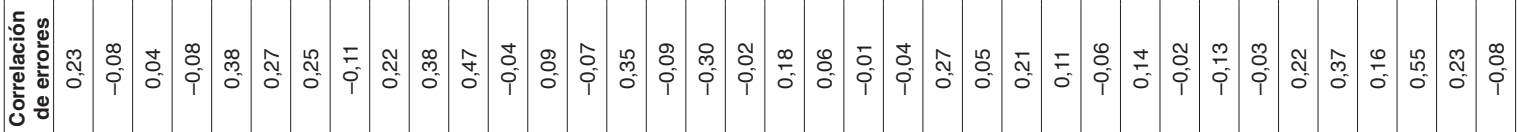

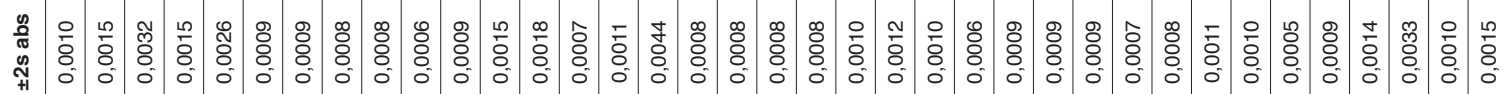

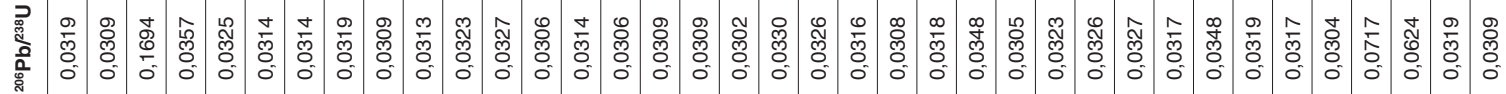

选

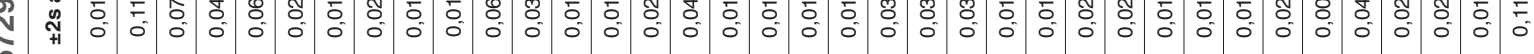

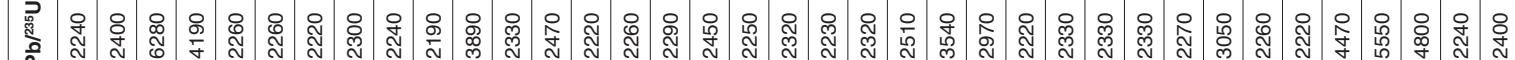

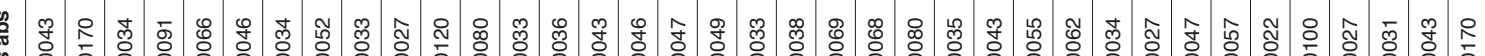

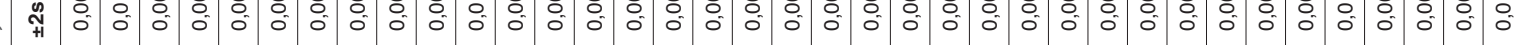

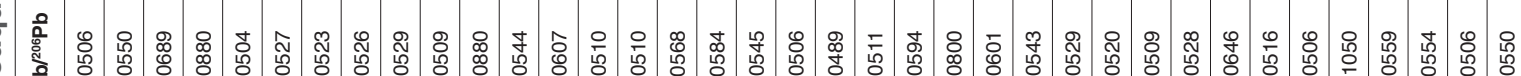
贾

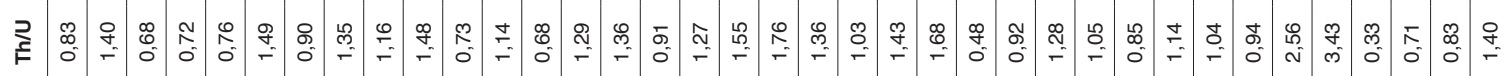

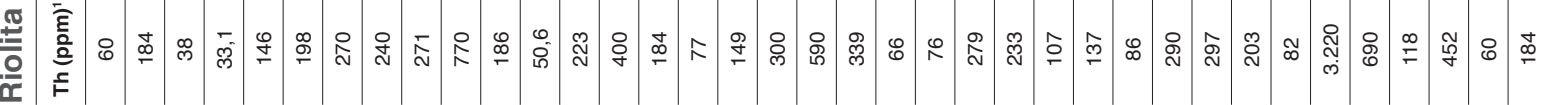

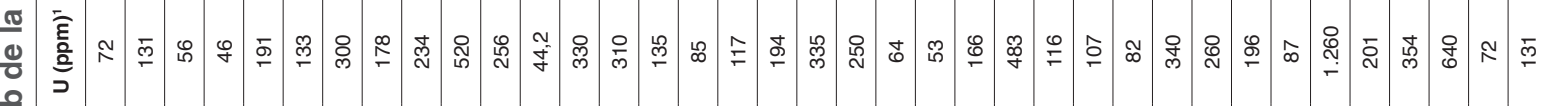




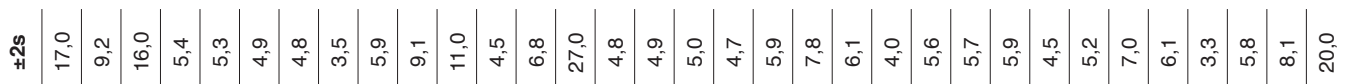

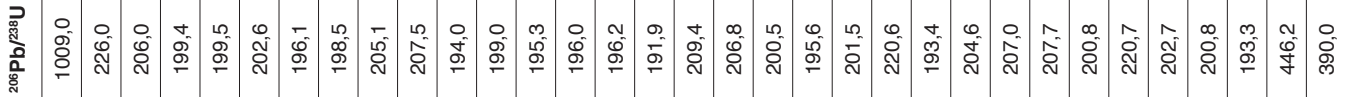

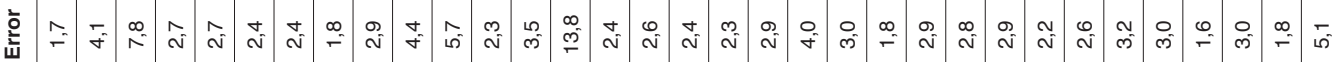

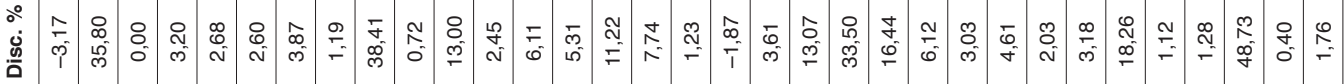

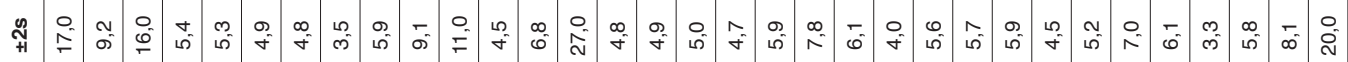

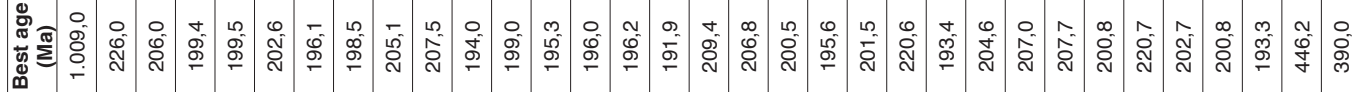

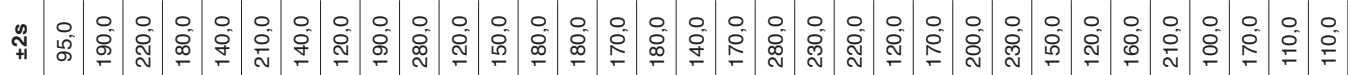

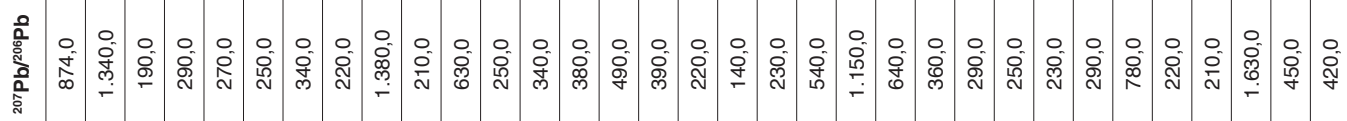
આ

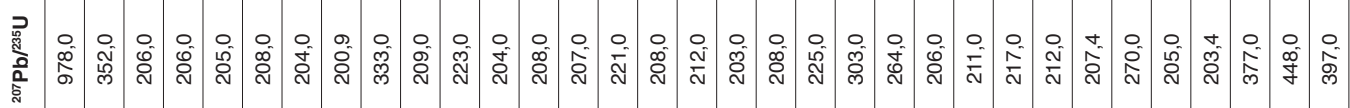

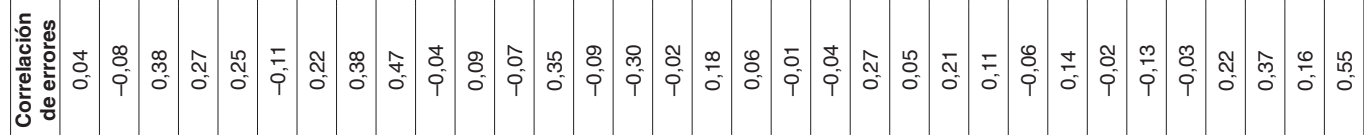

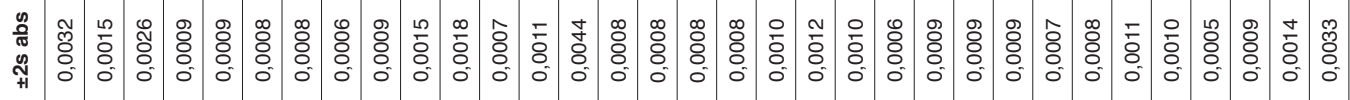

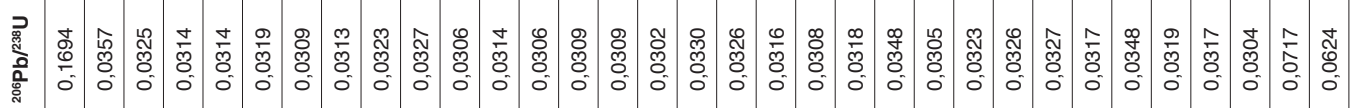

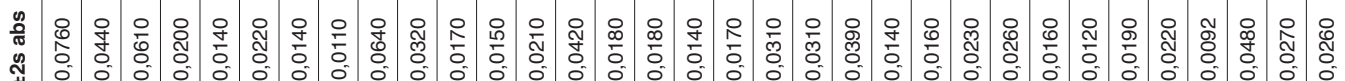

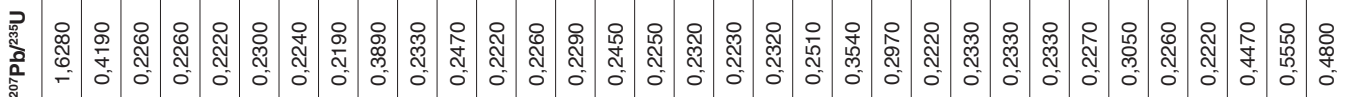

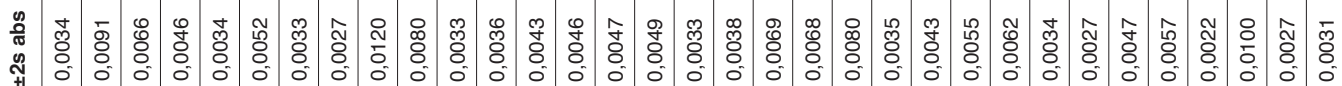

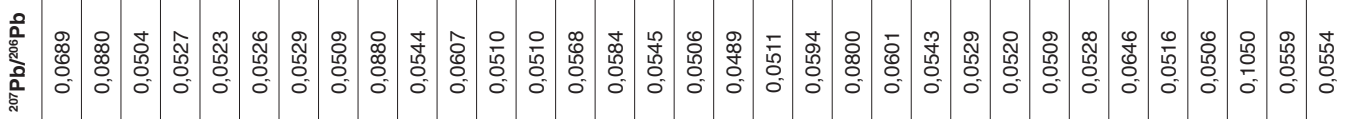

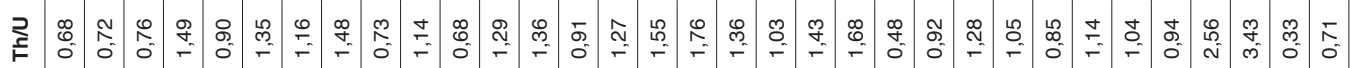

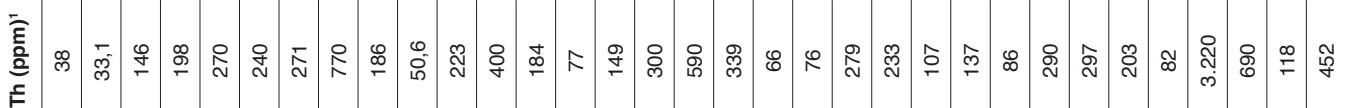

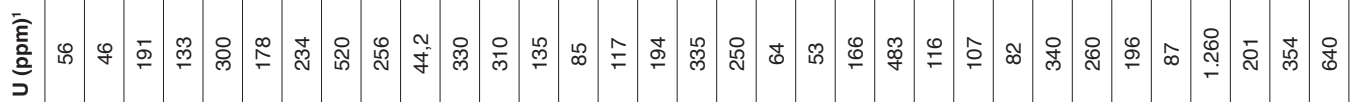

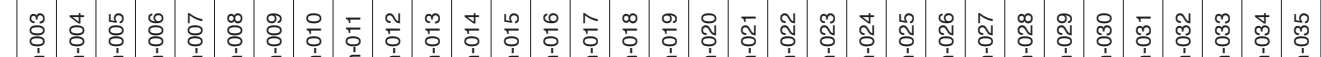

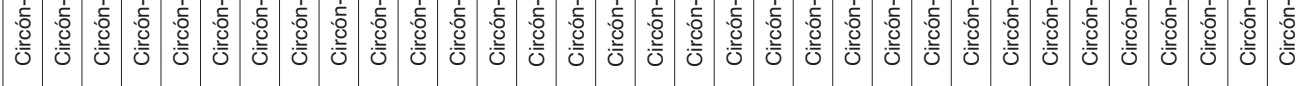

